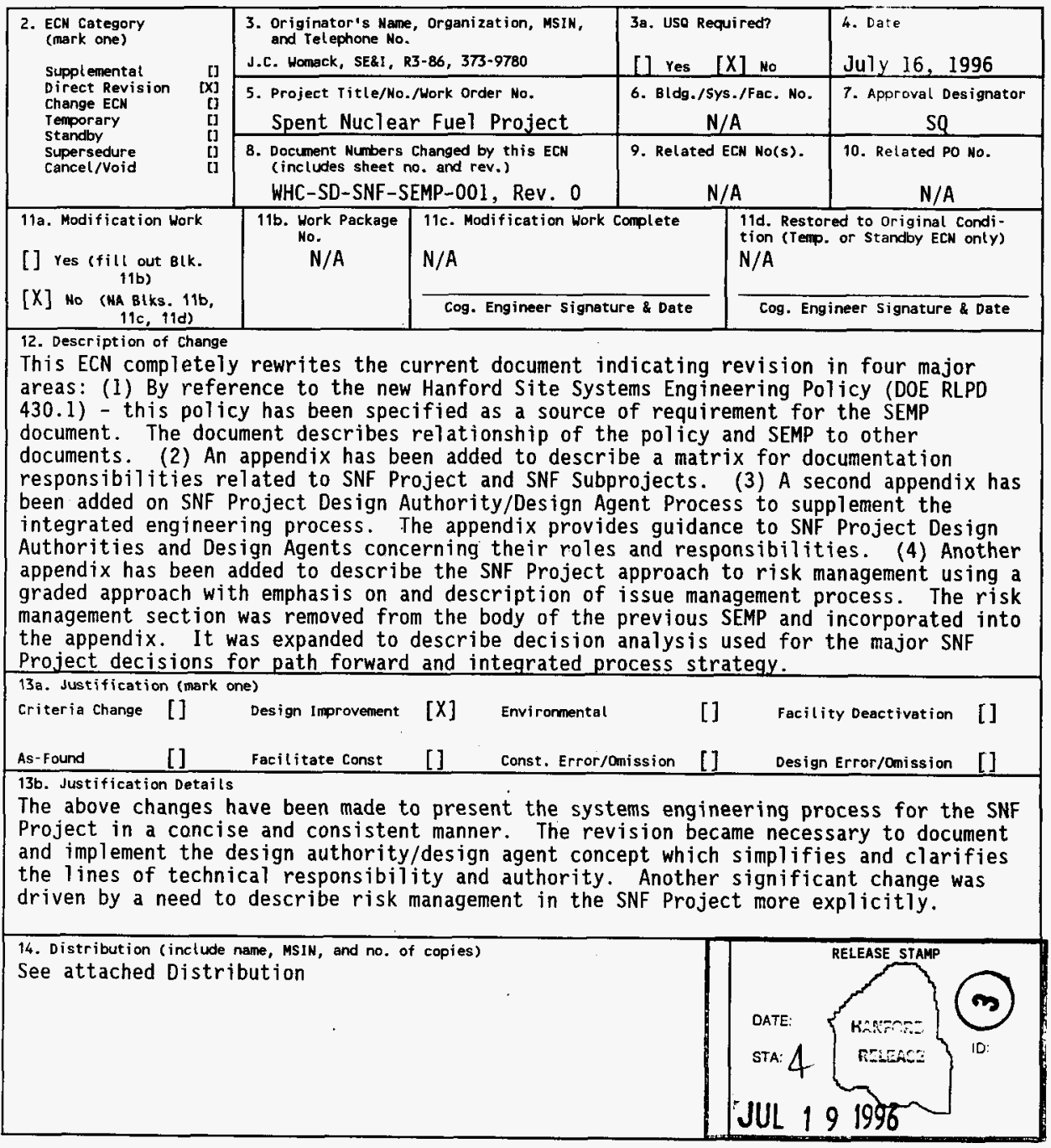




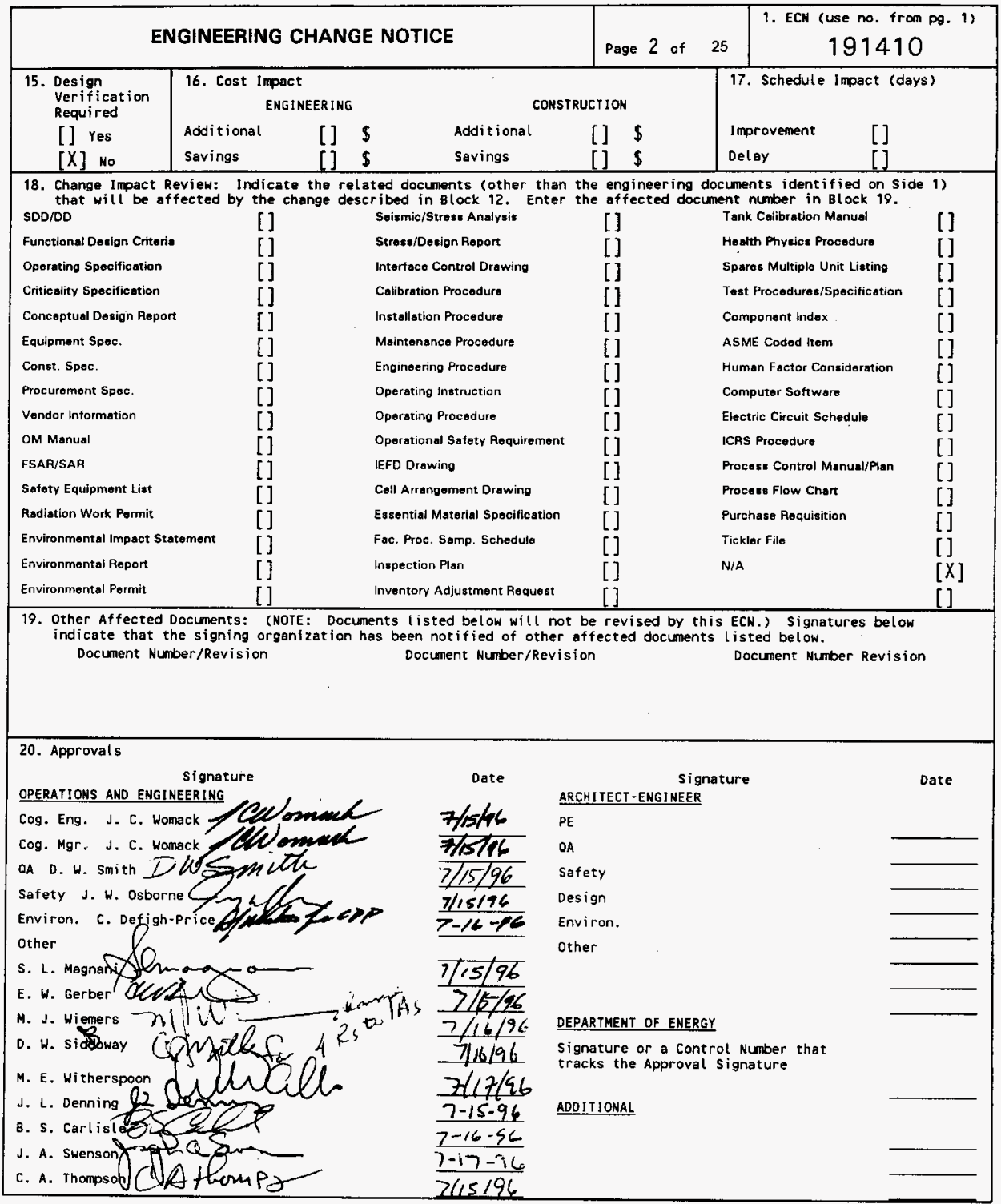


The following sections of the Spent Nuclear Fuel Project Systems Engineering Management Plan are revisẹd:

1. Table of Contents, Appendices, Figures, Tables, and Acronyms:

Replace Table of Contents, and lists of Appendices, Figures, Tables, and Acronyms entirely with revised sections.

2. Section 1.1, Purpose, Paragraph 1:

Replace the word in the sentence "Systems engineering is a disciplined approach to managing the project from top to bottom and from cradle to grave, to ensure that the project is doing the "right" things."

To "Systems engineering is a disciplined approach to managing the project from top to bottom and from cradle to grave, to ensure that the project is doing the "colrect" things."

3. Section 1.1, Purpose, Paragraphs 2 and 3, Replace the paragraphs with the following edited version:

The Purpese this Westing Hether This SNF Project Systems Engineering Management Plan (SEMP) describes the systems engineering approach, methods, and processes that are being will integrated with established $4+6$ engineering practices to enhance the engineering management of the SNF Project. It is not a complete treatise on the systems engineering discipline. The SEMP format has been tailored to meet specific needs of the SNF Project.

This SEMP satisfies the requirements set forth in the following documents:

4. Section 1.1, Purpose, Add the following requirements sources:

- Hanford Site Systems Engineering Policy, U:S Department of Energy (DOE) RLPD 430.1 (RL 1996a), which directs that systems engineering be implemented at the Hanford Site consistent with the Systems Engineering Criteria Document and Implementing Diractive, DOE RLID 4301 (RL 1996b);

- Project Management, WHC-CM-6-2 (WHC 1996a), states that where a SEMP is appropriate, it should be prepared in accordance with the Project Management System, DOE Order 4700.1 (DOE 1987);

- Systems Engineering Criteria Document and Implementing Directive, DOE RL1D 430.1, which provides direction on the implementation of systems engineering at the flanford Site, based on boE Order 430.1 .

5. Section 1.1, Purpose, Change the requirements sources as follows:

Systems Engineering (DOERtPQ 4900.1), which

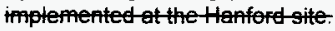

- Project Management System (DOE Order 4700.1), Chapter III, which states that the systems engineering management process is normally is controlled by adherence to a SEMP, prepared and maintained at the project level. (Noteithat DOE Order 470011 will be 
phased out and canceled after meeting implementation conditions of $L / f e-C y c l e$ Assessment Management, DOE Order 4301 (DOE 1995). Currenty, DOE Order 47001 is a compliance document and DOEOrder 43011 isnot);

- Spent Nuclear Fuel Project Management Plan, WHC-SD-SNF-PMP-011 (WHC 1995a), which directs that a SEMP be developed for the SNF Project; and

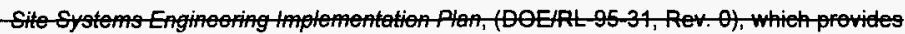
direetion on the implementation forstems thanfort.

6. Section 1.2, Scope and Context, Paragraph 1, Replace the paragraph with the following edited version:

\begin{abstract}
The This SEMP encompasses the efforts necessary to manage the AHA systems engineering implementation of for the SNF Project. This implementation applies to, and is tailored to; current and future sSubprojects, where "projets" and sub-tier activities; stbervient to SAF Projo physical activities supporting accomplishment of the SNF Project mission are referred to as Subprojects. Each sSubproject is an organizational entity, managed as a project responsible for design, development, fabrication and testing of a product. This includes project scope, configuration, cost, schedule, and performance. Subproject pParticipation in the subrojects is by e team, invelung involving all appropriate disciplines, including operations. Each sSubproject will prepare a management plan or work plan. Each subproject may prepare a system SEMP is not necessary if the SNF Project SEMP is adequate, as tailored in the subproject management plan. sSubproject size of the sumportant in an in

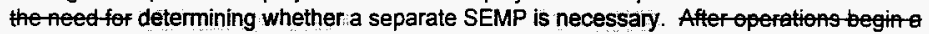
modified proeegs, tailored to maintentee ond operations is needed. This process is not ineluded in this-EEAP.
\end{abstract}

7. Section 1.2, Scope and Context, Paragraph 2, Insert the following as Paragraph 2:

This SEMP is intended for application to the design, development, fabrication, construction, test and startup of the Spent Nuclear Fuel Path Forward Subprojects leading to SNF Operations. After SNF Operations assumes responsibility for the system, a modified process, tailored to maintenance and operations is necessary. This process is not included in this SEMP. The K Basins engineering process is consistent with processes in this SEMP.

8. Section 1.2, Scope and Context, Paragraph 2, Replace the last paragraph with the following edited version:

Figure 1-1 depicts the relationship of this SEMP to the other systems engineering guidance documents $1-4$. The SNF Project SEMP content is derived from the Site: Systems Engineering, Site Systems Engineoring Management Plan (WHC 1996b), DOE RLID 430 t (RL 1996b), and the Spent Nuclear Fuel Project Management Rlan WHC-SDSNF-PMP-011) (WHC 1995a). Will be in agreement with the yet to be publighed WHE Hanfore Site SEMP, the U.6. Department of Energy, Riehtend Operationg Offie (Rt) Gystems Engineering Implementation Plan(DOElRt-95-34), and the SNF-Project Management Plan (AHHG-SD-SNF-PMP-OO1). All other systems engineering process interfaces will be through these documents. Because the transition from DOE Order 430.1 is not complete, this SEMP has maintained its consistency with DOE Order 47001 , as well. 
9. Section 1.2, Scope and Context, Figure 1-1:

Figure 1-1 was revised and updated extensively, and has been replaced in its entirety. Significant changes include the following:

- Within the DOE box:

- Replacement of old DOE SE policies and directives with the recently published SE policies and directives (i.e., RLPD 430.1 and RLID 430.1)

- Deletion of the Hanford Strategic Plan, Hanford Mission Plan, and Hanford Mission Management Plan, RL SE source documentation, and SE criteria document, consistent with DOE's new SE policies and directives.

- A note was added indicating DOE Order 4700.1 will be replaced by DOE Order 430.1 , when it is imposed on the contractor.

- Within the Site Systems Engineering Contractor box:

The issue Resolution (Process Management) Process box was added.

- Within the SNF Project box:

Boxes were added indicating that Subproject PMPs and SEMPs will be developed, as required.

10. Section 2.1, Spent Nuclear Fuel Project, Paragraphs 1 and 2, Replace the paragraphs with the following edited version:

Project organization The roles and responsibilities of the SNFProjedion are defined in the Spent Nuclear Fuel Project Management Plan (PMP), WHC-SD-SNF PMP-011 WHC 1995a). ENFFrojentention (PMP). This section ond is limited to, the roles and responsibilities associated with the implementation of SNF Projeet Systems Engineering in the Projects and Suprojects. Bocumentation responsibilities related to SNF Project and SNF Subprojects are defined in Appendix A which may be revised when the information is superseded by higher level Project documentation and integration (SE\&) Organization.

Successful implementation of systems engineering Systempenting SNF Projet is dependent on the active involvement of all SNF Project organizations in the development and implementation of the systems engineering processes, documents, and procedures, as defined in Sections 3.0 and 4.0. The Systems Engineering and Integration (SE\&I) organization provides systems engineering core competency, consistency between Subprojects,

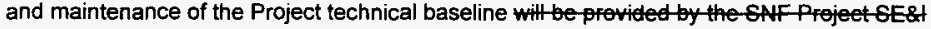
Orgenization. In addition, the SE\&I Organization wersenel will may facilitate development and upkeep of systems engineering processes, databases, and documentation products throughout the life of the SNF Project life.

11. Section 2.1, Spent Nuclear Fuel Project, Paragraph 3, Delete the entire paragraph:

The overall SAFF Projeet Division of Responsibility Matrix is anteine in the SNFFrojeet PAP Also, the PAAP provide ditionetinformation 
for the ONF Proje a whele. The respensibilities for allsystems engineefing tasks, as defined below, are presented with the deseription the tasts.

12. Section 2.2, Spent Nuclear Fuel Subprojects, Delete Paragraphs 1 and 2 as follows:

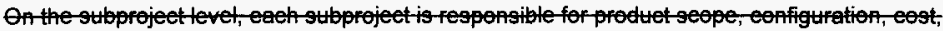

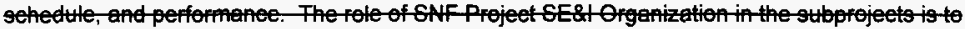

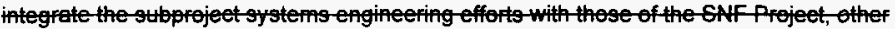
subprejects, the NatienalSNF Program (EM-37), and the Henford Site-Syatems Engineering. The SE\&tOrgenization will faeilitate the development andmaintenance of funetions and requirements

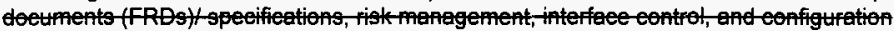
manement, as require betow.

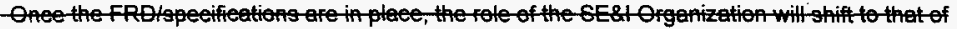
stppot of verifieation and validetion that requirements are being met, chengemanagement, continted integration of the stbprojeets, which ineludes interface entrol, and configuteation

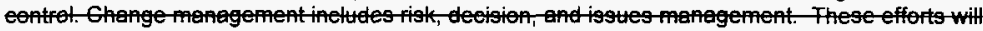

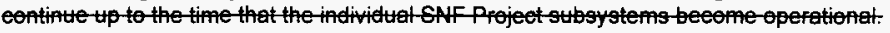

13. Section 2.2, Spent Nuclear Fuel Subprojects, Replace the deleted paragraphs with the following paragraphs:

A new Design Authority/Design Agent concept was established as part of the design process reengineering. This process focusses Technical responsibility and authority including implementation of systems engineering and integration activities, with the Subproject Design Authorities: This process, along with the Design Authority and Design Agent roles and responsibilities, has been implemented in the SNF Project, as described in Standard Engineering Practices, WHCCM-6-1, Interim Design Authority/Design Agent Engineering Process Requirements, EP 5:9 (WHC 1996c). Appendix B presents a description of this implementation.

Each Subproject is responsible for product scope, configuration, cost, schedule, and performance, Subproject Design Authorities are responsible for implementation of systems engineering processes and delivery of systems engineering products for their Subprojects to tie into SNF Operations. The SNF Project SE\&I organization may integrate the Subproject systems engineering efforts with those of the Project, other Subprojects, the National SNF Program (EM-67), and the Hanford Site Systems Engineering. The SE\&l organization will support development and maintenance of Subproject processes and documents.

Subproject roles and responsibilitles change throughout the Project life-cycle. Each Subproject ensures expected operation of the Structure, System; and/or Component (SSC), prior to tum-over to SNF Operations. After the Subproject Functions and Requirements (F\&Rs)/Function Design Criteria (FDC)/specifications are determined, the role of the SE\&I organization will shift to supporting the verification and validation (V\&V) that requirements are being met, coordinating change management, and maintaining interfaces with other Subprojects. Change management includes risk, decision, and issues management. 
14. Section 2.3, Spent Nuclear Fuel Operation, Add the following new section to the SEMP:

\subsection{SPENTNUCLEAR FUEL OPERATIONS}

The SNF Operations is currently comprised of $K$ Basins and Fuel Handing Operations (FHO): The K Basinsfocuses on existing facilities and 21 F FHO interfaces withPath Foryard activities to ensure that allsystems are in place, from the woinning of fuel retrieval to interimfuel storage in the Hanford Site 200' East Area.

The SE\& I will continue to ensure that the SNF Project Techinical Baseline is maintained through coordination of change management and interface control processes: The SNF Operations is responsible for operating and maintaining SNF facilites within the approved Safety Analysis, Standards/Requirements Identification Documients (SIRIDs), and Operational Design Criteria; and for maintaining the physical configuration control:

15. Section 3.1, Integrated Spent Nuclear Fuel Project Engineering Process, Replace the paragraphs with the following edited version:

The SNF Project integrated engineering process includes the systems engineering processes by which the SNF Project will defines its mission and determines the functions it needs to perform; the requirements

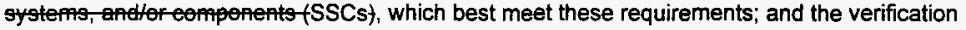
methods to be used to ensure that the design and operations requirements are met. This integrated process includes the Subproject design, development, analysis, fabrication, and testing leading to operations,-for on the subrojets degign. Figure 3-1 illustrates the basic integrated SNF Project engineering process. The basic process as shown in this figure is streamlined. Actual implementation requires feedback and interaction loops allowing for refinements, decision making, and

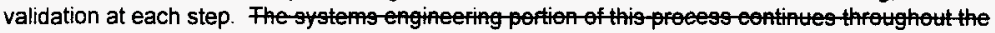
life of the engine ofing operations start, systems engineering activities focus on SNF Project integration, project

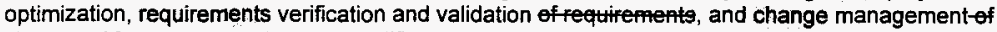
ehange. Afteroperations begin a modified proeso, tailored mainteneneentoperetions is needet. This ores is not in tuded in this SEMP.

The integrated engineering process will be implemented through the use of the Westinghouse Hanford Company (WHC) Controlled Manual system (WHC-CM) and the tailored systems engineering processes in the Hanford Site Systems Engineoring Manual, WHC-1P-1117 (WHC 1995b). The Hanford Site Systems Engineering Manual Henfor Engineering Mentul(WHGIP-1417). The tailered Henford Sitesystems Engineering Mantrat (AHG-1P-1177) procedures will be are used to implement the process, unless they the procedures are spelly defined specifically in this SEMP.

The System integration activities that continuing through the engineering process life include:

- Parametric Analysis;

- Trade Studies;

- Alternative Verifieation Analysis;

- Decision Analysis;

- Risk Analysis and Management; 


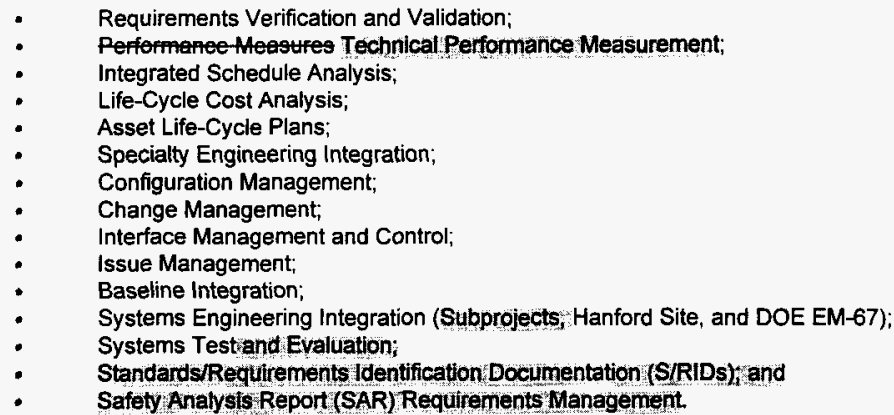

These activities are primarily managed primerily by other than the SE\&I organization, although they may be supported by the SNF Project SE\&I organization. integrated by the SNFFrojeet SESHOrganization staffessigned the stoprejeets to meet the oystemorengineering joetives.

16. Section 3.1, Integrated Spent Nuclear Fuel Project Engineering Process, Figure 3-1:

Figure 3-1 was revised and updated extensively, and has been replaced in its entirety. Significant changes include:

- Updating the process flow paths to more accurately represent the iterative SE process.

- Adding the boxes for the SNF Project Technical Baseline Description and Baseline Management Systems for managing the SNF Project requirements.

- Adding the Subproject-specific F\&R or FDC box leading into the Subproject Design Processes.

- The addition of critical SE Reviews included

- Updates and editorial corrections were made to the Systems Integration Activities box.

17. Section 3.1, Integrated Spent Nuclear Fuel Project Engineering Process, Delete the final paragraph:

Figure 3-2 presents sumary of the overallHenfort Site systems engineering proeess information interfaes. These interfaes revide mens integrathesystemsenginering effort at Hanfordung design, development, fabrieation, and tes of subsystems.

18. Section 3.1, Integrated Spent Nuclear Fuel Project Engineering Process, Figure 3-2:

Figure 3-2 was deleted. The remaining three Figures, $3-3,3-4$, and $3-5$, have been renumbered to be $3-2,3-3$, and $3-4$ 
19. Section 3.2, Systems Engineering Processes, Replace the paragraph with the following edited version:

The Specific processes that make up the systems engineering portions of the integrated engineering process are described in Sectons 32.1 through 32.8 . The processes not defined in these sections are described in Standard Enginooning Practices, WHC-CM-6-1 (WHC 1996\%. The Hanford Site Systems Engineering Manual, WHC-IP-1117 (WHC 1995b), provides a description of the specific procedoreds the proes

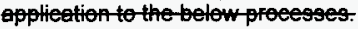

20. Section 3.2.1, Mission Analysis, Replace the paragraph with the following edited version:

The Mission analysis is the first step in the overall process. The analysis to defines the Project or Subproject problem, the initial unacceptable conditions, the acceptable final conditions, external constraints and interfaces, and resources required. It also estabiishes the basis for developing a system to resolve the Project or Subproject problem so that the mission can be accomplished. Thus, it the mission analysis defines, scopes, and bounds the Project or Subproject. The initial SNF Project mission analysis was conducted in 1994. This is documented in Spent Nuclear Fuel Projoct Mission Analysis Repont, WHC-EP-0790 (WHC 1994a). The

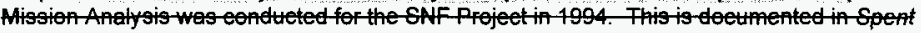

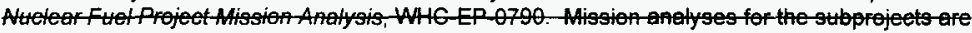

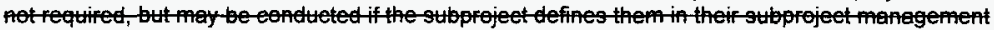
Mission analysis continues through the tife cycle to address items such as DOE redirection, cost and schedule performance, etc. Mission analyses for Subprojects are not required, but may be conducted if the Subproject defines them in Subproject management plans.

21. Section 3.2.2, Functional Analysis, Paragraph 1, Replace the paragraph with the following edited version:

The Functional analysis identifies the functions that must be performed in order to meet the mission. These functions are then developed at increasingly greater levels of detail to provide an increasingly explicit mission depiction of the misgion. In the SNF Project, these greater levels of detail become the functions of the Subprojects and SNF Operations. The SNF Project funetions mete to the Hanford-site funetions an SNF

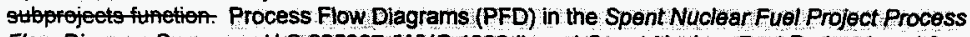
Flow Diagram Summary, H-2-825867 (WHC 1996d), and Spent Nuclear Fuel Project Level O Process Flow Dlagram, H-2-825868 (WHC 1996e), were produced to support the engineering process, and are a further development of the functions directly associated with chemical and nuclear processes.

22. Section 3.2.3, Requirements Analysis, Paragraph 1, Replace the paragraph with the following edited version:

Requirements analysis identifies the requirements associated with each function. Requirements define how well a function must be performed. The Requirements allocated to a Subproject functions become that Subproject's requirements. This analysis uses a top-down allocation of requirements from the primary sources of law, regulations, and DOE direction and orders, as well as requirements derived from studies, analyses, and tests. 
23. Section 3.2.3, Requirements Analysis, Paragraph 2, Delete the paragraph as follows:

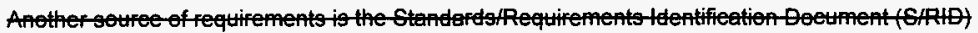
preess which identifies and validates enviremental, safety, health requirements forexigting

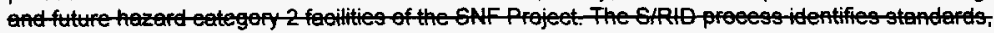

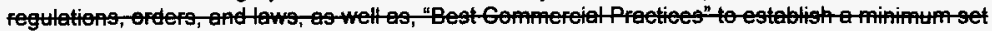

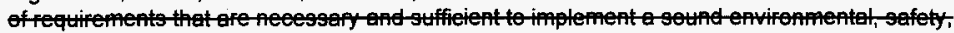

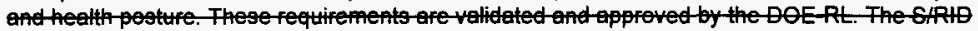
end-ystems nineering requirements will be integrate in a menner that is defined by the 1446 Henford Site Integration Orgentzation. During the operation the K Besing

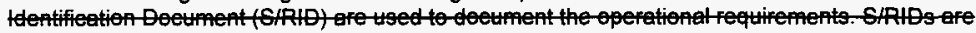

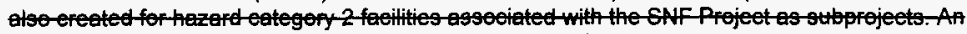

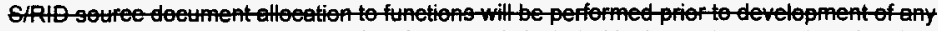

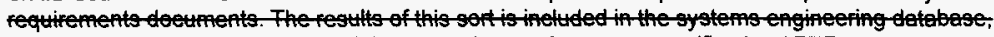

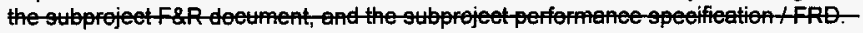

24. Section 3.2.3, Requirements Analysis, Add the following paragraphs after paragraph 1:

Functional requirements are derived by expanding functions untli they become detailed enough to define the requirements necessary to perfom a function. After quantitative values are defined for these requirements, the requirements become performance requirements After the functions have been decomposed into functional performance requirements, the requirements can be allocated to SSC Specifications are associated with SSC.

The S/RID process identifies and validates environmental, safety, and health requirements for existing and future Hazard Category 2 facilities of the SNF Project The S/RID process identifies standards, regulations, orders, and laws, as well as, "Best Commercial Practices" to establisha minimum set of requirements that are necessary and sufficient to implement a sound environmental, safety, and health posture. These requirements are validated and approved by DOE-RL.

Other requirements sources include design studies; interfaces, analyses (including safety analyses with resulting Operating Safety Requirements and Technical Safety Requirements); trade studies; conceptual design and verifications associated with a SSC. Safety analy ses that result in the Project SAR are examples of sources of derived requirements. These derived requirements must be integrated into the requirements of the Subprojects and/or Project after the initial requirements analyses. The definition of these requirements throughout the design process results in the need for update, addition, revision, and modification of the requirements database and documentation. The S/RIDs and derived systems engineering requirements are integrated and maintained. Another source of SNF Project derived requirements are the studies that produce the U.S. Nuclear Regulatory Commission (NRC) equivalency requirements, as documented in the Spent Nuclear Fuel Project Path Forward, Additional Nuclear Regulatory Commission Requirements, WHCSDDSNFDB $=003$, (WHC 1995c).

During facility operation, S/RIDs and SAR are used to document the operational requirements: The S/RIDs are also created for Hazard Category 2 facilities associated with the SNF Subprojects. The SAR, along with S/RIDs, provides a source of derived safety requirements. Identification of the specific requirements is included in the Subproject F\&R or FDC document, and the Subproject requirements specification, as necessary and appropriate.

The SNF Operations F\&Rs are the responsibility of the SNF Project FHO Organization. 
25. Section 3.2.4, Alternatives Analysis, Replace the paragraph with the following edited version:

The Alternatives analysis identifies alternative solutions or SSC configurations (architectures) for functions that meet the requirements of those functions. These analyses are conducted at the Project and Subproject levels, as appropriate, town to and ineluding components.

26. Section 3.2.5, Trade Studies, Replace the paragraph with the following edited version:

Trade studies are a portion of the engineering process of comparing or trading the strengths and weaknesses of alternative approaches or attributes. Fhey Trade Studies are the basis for selection of alternatives approaches or attributes. The Trade studies shall include decision criteria that incorporate mission objectives and stakeholder values, and that will result in selection of

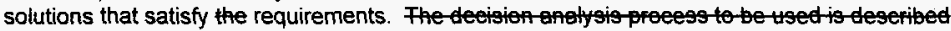
below. These trade studies are performed at both the Project and Subproject levels.

27. Section 3.2.6, Requirements Specification, Replace the paragraph with the following edited version:

A requirements specification is a document that is prepared to support development and/or acquisition of a SSC. The requirements specification can take the form of a FRO for WHIG internaldevelopment use or a performanee-specifieation for

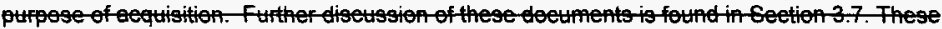
doeument are prepred be used for SSC development by WHC, or to support procurement from a vendor. These documents are further discussed in Section 3.6. These documents are the responsibility of the Subproject Design Authorities.

28. Sections 3.2.7, Design Construction, Add the following section:

\subsubsection{Design and Construction}

Design and construction processes associated with the SNF integrated engineering process are defined in Standard Engineering Practices, WHC-CM=6-1 (WHC 1996c) and Project Management, WHC-CM-6-2 (WHC 1996a), and are not repeated in this document:

29. Sections 3.2.8, Test, Add the following section:

\subsubsection{Test}

Testing will occur throughout the facility and system life cycle, including that testing that is required to support design, safety analyses, operational readiness, and post startup process optimization. This life-cycle testing is described in the Spent Nuctear Fuel Project Integrated Testing Strategy, WHC SD SNF-CM-004 (PNNL 1996) Final testing includes acceptance testing, conducted by the Subproject to verify that the system has met design requirements sand operability testing, conducted by appropriate operations organizations to ensure that operations requirements have been met. The acceptance and operability testing will be addressed in the stait-up plan currenty being developed by the SNF Project FHO. 
30. Section 3.3, Decision Analysis, Delete the entire section as follows:

\subsection{BEGISION ANALYSHS}

Benisionanatysis is tred to:

Greate logieally defensible decisiens by doetmenting the decision proeess;

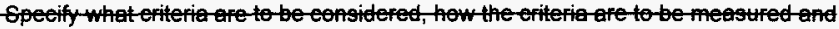
evaluated, and the relative importane of the eriterie;

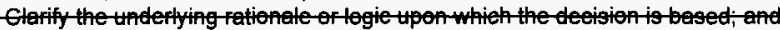

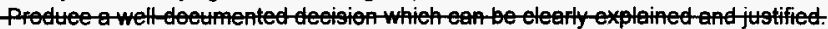

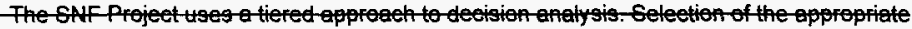

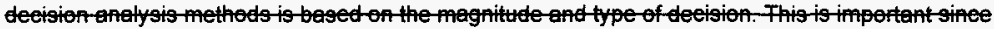
meny decisiens are based on analyses performed by other contracts and-stbeentraetors,

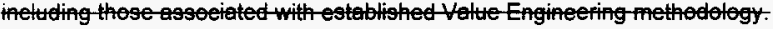

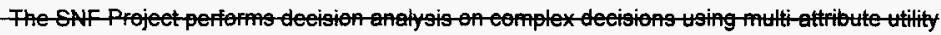

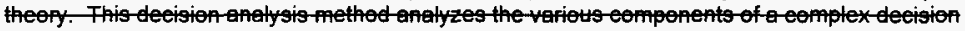

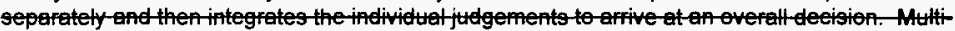

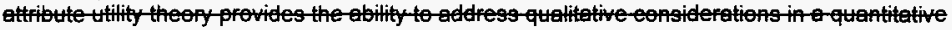
methodology. This decision anelysis method is used andoetmented in Eeetion 5 of volume 2 of

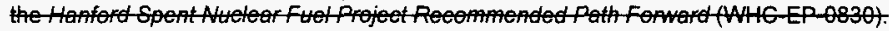

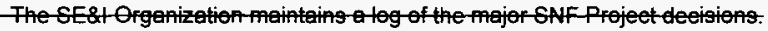

31. Section 3.3, Technical Baseline

Because Section 3.3 was deleted, renumber Section 3.4 and associated sections to be 3.3 , etc.

32. Sections 3.3. Technical Baseline, Replace paragraphs 1 through 3 with the following edited version:

\subsection{TECHNICAL BASELINE}

The SNF Project technical baseline is the documented body of technical information associated with the people, products, and processes required to accomplish the SNF Project mission. The SNF Project technical, schedule and cost baselines comprise the integrated SNF Project baseline. The Figure 3-2 depicts the relationships of these baselines, and re illustrated in Figufe 3-3. This figure shows the progression from functions and products, to the Work Breakdown Structure (WBS), to the schedule, and in turn, the cost baselines. The SNF Project organizational

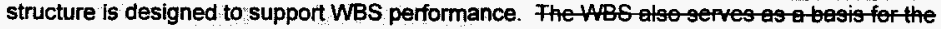
organizational struetufe of the SNF Project. The eufrent SAFF Projectiopresented in the-SNF ProjetPAP. The SNF Project organization is presented in the currently published SNF Project organization charts.

Because Ene the SNF Project is comprised of Subprojects that are at various levels of maturity and development, the technical baseline is composed of Subproject technical baselines that are also at various development stages progressively more-detailed technical baselines have different names. Table 3-1 describes the progression of technical baselines. These baselines are under configuration control after initial approval. 
Figure $3-4-3-3$ illustrates the relationship of these baselines to the integrated engineering process. The technical baseline contents are primarily are documents in the SNF Project that result from other engineering activities. The baseline development process presented refiects the SNF Project's own needs. The SNF Project baseline development integrates with the Hanford Site baseline development-a The Technical Baseline Description establishes the requirements baseline down to the Subpro eis $_{\text {s }}$ Subproject details are the prerogative of the Subprojects: Only the Functional Requirements technical baseline shall be developed at the SNF Project Subproject levels. Subproject and operationstorgangations develop all other technical baselines. The development of ather technieatbelines is performed the opejos?

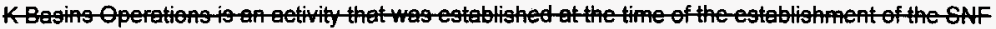
Pfojet. KBasins organization was in progressat the time the SNF Project was established and integrated into the SNF Project At that time, KBasins organization was integrated into the SNF Project to continue $K$ Basins maintenance and operations of the $K$ basing in a safe and environmentally compliant manner during development of the other SNF Project portions. AN Such, KBasins organization Projeet. As as an established AsBuilt Configuration Technical Baseine, Configuration Management Plan, Operational S/RIDs, and $S A R$, that serve as a basis for risk management. For these reasons, K Basins Opetions organization does not need the steps leading to the As-Built Configuration Baseline

33. Sections 3.3. Technical Baseline, Figure 3-2:

Because Figure 3-2 was deleted, renumber Figure 3-3 to be Figure 3-2, Integrated Baseline Development. This figure was revised to change the position of the Cost and Schedule Baseline Elements and to retitle the Schedule Baseline as the "Master Baseline Schedule."

34. Sections 3.3. Technical Baseline, Figure 3-3:

Because Figure 3-2 was deleted, renumber Figure 3-4 to be Figure 3-3, Spent Nuciear Fuel Project Integrated Engineering Process. This figure was revised and updated extensively, and has been replaced in its entirety. The concept of Operational Baseline has been added; and other updates were made to be consistent with Figure 3-1.

35. Section 3.3.1, Functional Requirements Baseline, Replace the paragraph with the following edited version:

The SNF Project-level Functional Requirements Baseline describes the SNF Project approach, top-level requirements and constraints, and the top-level functional and architectural features. This baseline provides the necessary details for start of Subproject conceptual design . The Functional Requirements Baseline has its basis in the Systems Engineering Functions and Requirements for the Hanford Cleanup Mission: First Issue, WHC-EP-0722 (WHC 1994b). This baseline in developed by analyzing the contents of these site baselines and applying the information to the SNF Project. This is documented in the Project Technical Baseline Description. The SNF Project Functional Requirements Baseline is a component of the Hanford Site Performance Baseline. The SNF Project SE\&I Organization develops this baseline on at the SNF Project level, and the Subproject teams further develop this baseline at the Subproject levels. 
36. Section 3.3.2, Performance Requirements Baseline, Replace the paragraph with the following edited version:

The contents of each Subproject baseline represents the performance requirements and SSC configurations (architectures) chosen to accomplish the SNF Project mission. Fhis The Performance Requirements Baseline forms the basis for initiating preliminary design.

37. Section 3.3.3, Design Requirements Baseline, Replace the paragraph with the following edited version:

The contents of each baseline expands on the technical requirements allocated to each subproject, delineate more-detailed derived requirements, and add technical requirements that reflect design configuration (architecture) decisions and preliminary design. These Design Requirements Baseline becomes the basis for definitive design.

38. Section 3.3.4, Design Configuration Baseline, Replace the paragraph with the following edited version:

The Design Configuration Baseline shows the progress of the Subprojects in refining the design and developing the "build-to" design packages. This The Design Configuration Baseline forms the basis for the beginning of construction and testing

39. Section 3.3.5, As-Built Configuration Baseline, Replace the paragraph with the following edited version:

The As-Built Configuration Baseline do completed construction, and validates the operational basis. The As-Built Configuration Baseline These is the technical basis for the start of operations. Constituents of the As-Built Configuration Baseline are components of the Site As-Built-Operationel, and Baselines.

40. Section 3.3.6, Operational Baseline, Add the following section:

\subsubsection{Operational Baseline}

The Operational Baseline includes updated operational procedures; SAR, final facility S/RIDs, and physical configuration design and description. Operational Baseline items are the basis for continuing operations, and will be used as the deactivation activities starting point.

41. Section 3.4, Reviews:

Because Section 3.3 was deleted, renumber Section 3.5 and associated sections to be 3.4 , etc.

42. Section 3.4, Reviews:

Delete Table 3-2.

43. Section 3.4, Reviews, Replace the paragraph with the following edited version:

This section describes the SNF Project and Subproject reviews. The SNF Project will adapt the review process presented the 


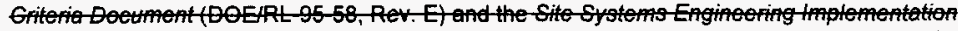
Plan, (BOEARL-95-31, Rev. O) to reflect the SNF Project's own needs. Also, In addition; each Subproject will adapt or tailor the reviews, as appropriate, to theif its needs. The number and type of reviews described below herein are tailored from those described in $10 E 4700.1$. the Project Management System, DOE Order 47001. (DOE 1987). These reviews are reviews described in Standard Engineening Practices; WHC-CM-6. 1, Desion Yerification Requirements: EP 4.1 (WHC 19960), and will be in accordance with this EP, as tailored for the Subprojects and documented in the PMP for each Subproject. thesystemgineering

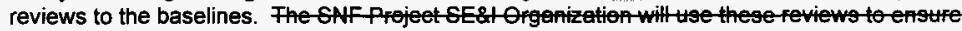
the the ffio of of the of toprojects are integrated.

The verifiention Requirements V\&V provide a mechanism to

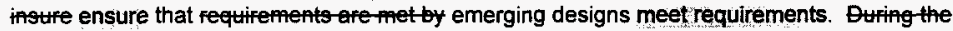

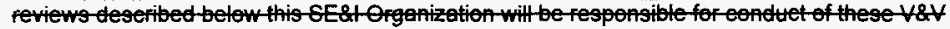
funetions.

44. Section 3.4.1, System Requirements Review, Paragraph 1, Replace Paragraph 1 with the following edited version:

This Systems Requirements Review (SRR) evaluates the Functional Requirements Baseline. The SRR is conducted to gain concurrence on the SNF Project objectives, approach, and top-level functions, requirements, architecture, and interfaces. The SRR is conducted by the SNF Project

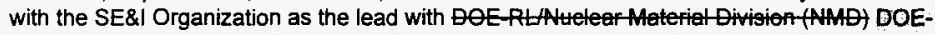
RL/Spent Fuel Division (SFD) co-chairing the review. The DOE-RL-Assistant-Menager for Alagent The SRR is an SNF Project-level review.

45. Section 3.4.1, System Requirements Review, Add the following paragraphs after Paragraph 1:

A SRR normally would have been conducted prior to the initiation of the Subprojects' design phase, and would consist of a high tevel review of SNF Project objectives, systems engineering approach, and Project level functions, requirements, architecture, and interfaces, as appropriate: Conducting a SRR was not appropriate until the technical baseline stabilized with the approval of the Integrated Process Strategy, followed by issuance of the Spent Nuclear Fuel Project Tochnical Baseline Description - Fiscal-Year 1996 (WHC 1995d) in November 1995.

The DOE-RL/SFD concurred with the Site Systems Engineering, Systems Engineering Management Plan (WHC 1996b), Spent Nuclear Fuel Project Configuration Management Plan (WHC 1995e), and Spent Nuclear Fuel Project Interface Control Plan (WHC 1995f); approved the Multi-Year Program Plan (MYPP) Revision, evaluated and audited the SNF Project Baseline Management System database, conducted on-board reviews, and conducted Subproject systems engineering assessments. The DOE-RL/SFD also provided top slevel programmatic decision making and direction. The DOE-RLSFD determined the total of these to be equivalent to conducting a SRR.

46. Section 3.4.2, Conceptual Design Review, Replace the paragraph with the following edited version:

Theserente A Conceptual Design Review (CDR) is a Subproject review that evaluates the Performance Requirements Baseline. These stbprojeet reviews are, and is conducted by a SNF Subprojects. The approvel authorty is the 
47. Section 3.4.3, Preliminary Design Review, Replace the paragraph with the following edited version:

Thereliminary Design Review (PDR) is a Subprojectreview that evaluates the Design Requirements Baseline, Fhesespere and is conducted by a SNF

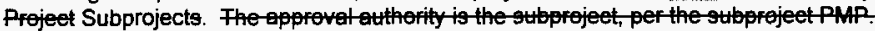

48. Section 3.4.4, Definitive Design Review, Replace the paragraph with the following edited version:

There

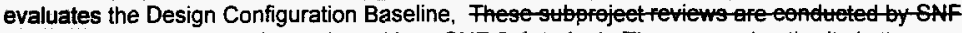
Projeet-subprojeets. and is conducted by a SNF Subproject. othejet, the-stbpojetPIP.

49. Section 3.4.5, As-Built Design Review, Replace the paragraph with the following edited version:

The An As-Built Design Review (ADR) evaluales the As-Built Configuration Baseline. The ADR fevevaluates the as-built Subproject's SSC configurations (architecture) to ensure that the configurations function properly and meet the requirements of the contract and the approved design. These Subproject reviews are conducted by SNF Project

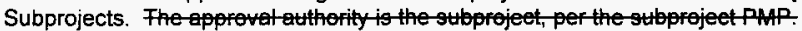

50. Section 3.4.6, Operational Readiness Review, Add the following section:

\subsubsection{Operational Readiness Review}

An Operational Readiness Review (ORR) is a major review sponsored by the DOERUSFD. The ORR is used as a verification that a facility is ready for operation. The ORR will address, as a minimum:

- Facility readiness;

- Facility ability to perform its assigned mission;

- Facility operational safety;

- Facility maintenance readiness;

- Operational training; and

- Required permits and procedures completion.

The DOE ORR shall be conducted after the test phase is complete, prior to start up.

51. Section 3.5, Systems Engineering Technical Documentation:

Because Section 3.3 was deleted, renumber Section 3.6 and associated sections to be 3.5 , etc.

52. Section 3.5, Systems Engineering Technical Documentation, Replace the paragraph with the following edited version:

Technical documentation consists of documents that contain the information that comprises the SNF Project technical baseline. Table 3-1 presents a list of the SNF Project technical information 
and their relationship to the technical baselines. The majority of this documentation is not unique to systems engineering, ; engineering practices documented in Standard Engineoring Practices WHC-CM-6-1

(WHC1996C).

53. Section 3.6, Requirements Documentation:

Because Section 3.3 was deleted, renumber Section 3.7 and associated sections to be 3.6 , etc.

54. Section 3.6, Requirements Documentation, Add the following sections:

\subsection{REQUIREMENTS DOCUMENTATION}

\subsubsection{Spent Nuclear Fuel Project Specification}

The SNF Project Specification states the technical and mission requirements for the SNF Project, derived by the Hanford Technical Integration organization, as doctimented in the Hanford Site Cleanup Specification and contained in the Hanford Site Technieal Baseline Database. The Hanford Site-level requirements for the SNFProject Wil be provided to the SNF Project in this specification, which will become the technical basis for the SNF Project Mutt Year Work Plans (MYWP) and MYPP.

\subsubsection{Functions and Requirements Documentation}

The SNF Project Management Plan defines a need for an F\&R or FDC document. This document is a statement of the Subproject, or operations F\&R to a level consistent with the Subproject objective. The Subproject F\&R or FDC contains, as a minimum, all functions allocated to that Subproject, and requirements allocated to the subproject that affect performance of that Subproject and are not contained in the Subproject acquisition F\&R. Individual Subprojects may prefer to include all F\&R allocated to that Subproject.

The SE\&I organization may support development of the F\&R document and may ensure that it is consistent with the Subproject requirements specification. These sets of F\&R documents are the Subproject F\&R.

\subsubsection{Requirements Speclfication}

As requirements are allocated to a SSC, the requirements are placed in the requirements specification, which is associated with that SSC. The requirements specification is for use by a Subproject for acquiring SSC. Performance or functional specifications are to be prepared in accordance with Standard Engineering Practices, WHC-CM-6-1, Enqineering Specification Requirements, EP-12 (WHC 1996c), as single-use, non construction engineering specifications. Unless tailored by the Subproject guidelines for the content and format of these single-use, engineering specifications are contained in Engineening Practico Guidelines, WHCIP 1026, EP G-1.2 and Appendix Q (WHC 1996f).

A requirements specification is a document that is prepared to support development and/or acquisition of a SSC. The requirements specification can be either a performance or functional specification. The requirements specifications state performance (technical) and mission requirements, and allocate them to functions and SSC. 


\subsubsection{Basellne Documentation and Database}

Using the results of the mission and functional and requirements analyses, a single integrated SNF Project Baseline has been established for requirements integration and maintenance. This electronic database, the Baseline Management System (BMS) is designed to contain the Project baseline information. The SNFProject Techntgal Baseline Description (WHC 1995d) provides an integrated description of the SNF Project and the data that form the Project basis

55. Section 4.1, Functions and Requirements Management, Replace the paragraphs with the following edited version:

Requirements traceability ensures that the technical basis for engineering decisions is maintained, which in tum allows effective resource planning and use:

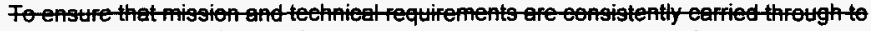
implementetion, the SNF Projeet-will employ computer-based requirements menegement

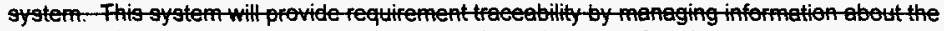
soure the requirement, as wellas its allecation to lower tier funetions or enditem produts

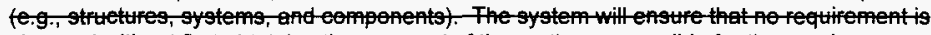
ehanged without first obtaining the approvel of the parties responsible for the requirement

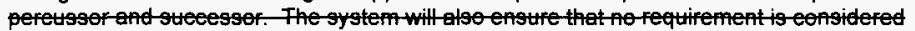
implemented until all of its olloeated perts are implemented. The SNF Projeet will use this system

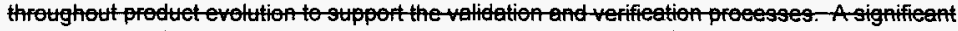
pert of the requirements management system is a database of allfunetions and requirements defined by the-SNF-Projectand its subprojects. This databere-is implemented by the-SE\&t

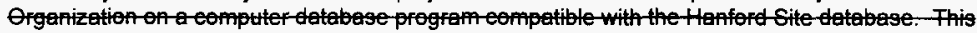
database is maintained until requirements specifieations (FRDs of performanee-speeifieations) are

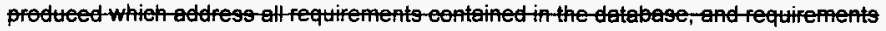
compliance is verified. Gonfiguration control of the requirements in the project with be implemented

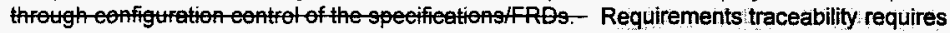
information regarding the requirement source, as well as the requirement's allocation to lower-tier functions or end-item products (e.g., SSC). No requirement is changed without first obtaining approval from the parties responsible for the requirement precursor and successor. All F\&R allocations are stored in an electronic database for retrieval; sorting, and report generation.

As the technical baseline matures, the requirements specifications will be replaced by more-detailed, lower-level specifications. These lower-level specifications, besides being more detailed, may change some of the requirements in the requirements specifications. As these lower-level specifications are developed, the Technical Baseline will be updated so that it contains all the requirements currently identified by the SNF Project and Subprojects. After requirements specifications are developed requirements will be traceable to their respective requirements specification. This ensures that all requirements are traceable through all levels. The requirements on be developed. During this decemposition all requirements willbe traee ble to the database. Once requiremento opecifieations are developed, requifemento willbe

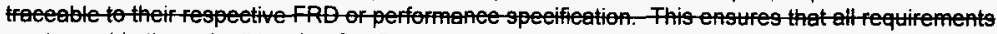
are traceable hrough all levels. Gonfiguration managementmaintaing an ontrols

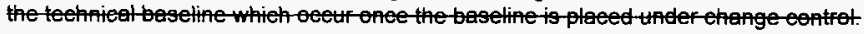


56. Section 4.2, Configuration Management, Replace the paragraph with the following edited version:

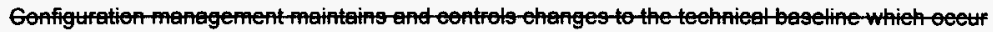
onee the baseline is placed under change control. The SNF Projeet will perforfineonfigutration menegement in aeeordanee-with The The technical baseline will bemaintained and changes will be controlledjin accordance with the Spent Nuclear Fuel Project Configuration Management Plan. (A4F,-4995) RH1O $1995 \mathrm{e}$ ).

57. Section 4.3, Technical Interface Control, Replace the paragraph with the following edited version:

The SNF Project will was established dand will maintain an interface control process coordinated by an Interface Control Working Group (ICWG). The ICWG is a team of

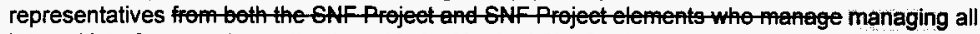
internat interfaces and coordinating with the Hanford Site for resolution of interfaces external to the SNF Project. The ICWG provides traceability, coordination, and documentation of interface definitions using Interface Control Documents (ICDs). The Spent Nuclear Fuel Project Interface Control Plan, (HA, 1995) WHCSD-SNFECM-003 (WHC 1995f) contains more complete information on the interface control activities that the SNF Project will conducts.

58. Section 4.4, Risk Management, Delete the first two paragraphs and replace them as follows:

Aenegers are charged with the respongibility of meking deeisions which inherently heve

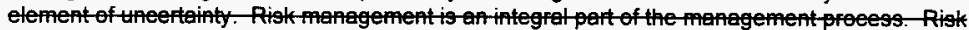
mentement is define as a method of maneging that eoneentrates on identifying and ontrolling the are of events that have a petentiat of eatsing thwented henge. Risk manegement

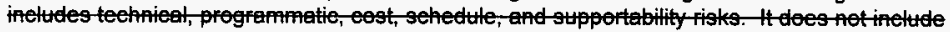
"ingtrance rigk," "safely rigk," or "gecident rigk."

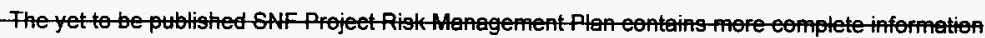
on the rist manegement by the SNF Project.

The SNF Project has undertaken an aggressive schedule with the goal of earty fuel removal from the $K$ Basins to reduce risks to public and employee health and safety and the environment Disciplined implementation of risk management is required to ensure that the accelerated schedule does not result in undue safety environmental, technical, schedule, nor financial risks. Several management methods are being applied to ensure a reasonable understanding and sound management of such risks. These methods include:

1. Implementation of an issues management program for addressing issues at the Project and Subproject levels;

2. Use of disciplined systems engineering and project management processes; and

3. Implementation of a general design strategy towards robust designs based on existing technology.

Risk management processes within Hanford Site projects have their basis in the Site-Wide Systems Engineering Risk Management Plan, which is an attachment to Site Systems Engineering, Systems Engineoring Management Plan (WHC 1996b).

Risk management in the SNF Project is performed at multiple levels, using a graded approach, with emphasis on issues management Major programmatic decisions have employed 
quantitative or semi-quantitative analytical risk-management techniques, such as statistical evaluations or multi-attribute decision analysis Ongoing Project and Subproject risk-management activities emphasize fechniques that adjust to the accelerated pace of Project activities, including qualitative techiniques such as issues management Appendix $C$ describes the SNF Project approach to tiskmanagement.

59. Section 4.5, Work Breakdown Structure, Replace the paragraph with the following edited version:

The SNF Project WBS represents all of the work, and only that work, that is required to achieve the end item states that have been defined as a result of the mission, functions, requirements, and alternatives analysis of the systems engineering process, including the systems engineering process itself. The SNF Project WBS is contained in the SNF Project PNP MYPP. The WBS results directly from the systems engineering process, as defined above previously. Subsequent WBS updates and expansions the WBS result from "design" efforts implemented by the Subprojects and management process efforts resulting from implementation of the subproject Program Management Plans.

The subprojects will use the SNF Project WBS as a basis for developing WBS for their specific Subprojects. The SNF Project WBS also provides an administrative interface to other programs and projects on the Hanford Site.

60. Section 4.6, Schedule, Replace the paragraphs with the following edited version:

The SNF Project Master Baseline Schedules Systering the engineering and technical activities performed by the SNF Project. These schedules provide SNF

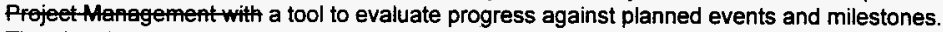
The planning process, which includes schedule defining, cost estimating, and budgeting, is based. on the WBS. Aslowertevetsehedules, systems

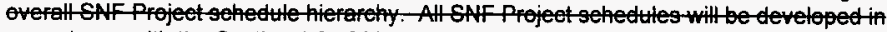

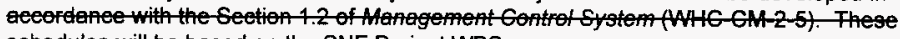

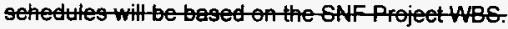

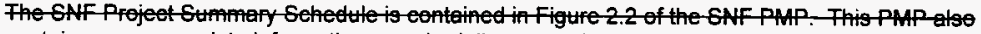
conteins more complete informetion The Project Master Baseline Schedule is summarized to a Level 1 Management Summary Schedule. The Management Summary Schedule is employed in the Plan of the Week to show weekly status:

61. Section 4.7, Performance Measurement, Delete all paragraphs and replace with the following paragraphs

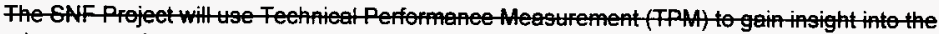
adequey and meturity of the design, identify key par meters to berified by the test evaluation efforts, and provide inputs into-verall-SNF Projet management and risk-manogementThe TPM consist of selecting key technied parameters and traeking these peremeters,

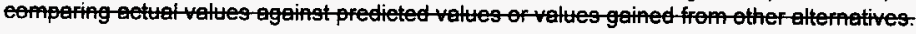

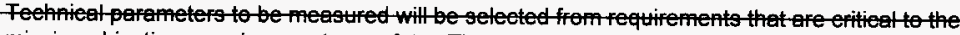
misrion objectives, environment, or sefety. Theseperemeters will be identified during the requirements develo ment preess. Parameters selected for treking will be key indiectorg and

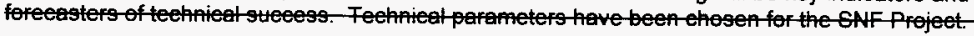


These parameters listed as "Measures-of Effectivenesg" in Seetion 11, Votume-tof the Spent

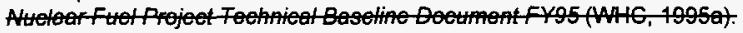

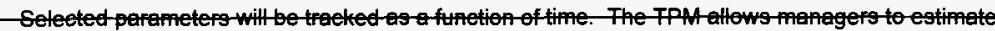
the maturity of the design of the performance of allernatives any time. Bomepormeters will

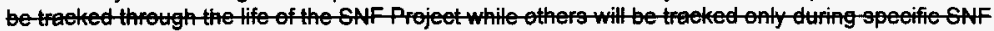
Project phases or to identify endresolve-speeifieriskisotes.

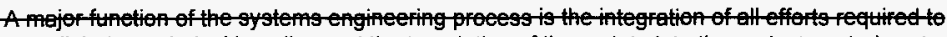
establigh the tehnied baseline and the transtation of these data into the project controlsystem. Al the Henfordsite, thioproje entroloystemis the Henford Site Manogementsyom (Rt 5000.12$)$.

Performance measurement in the SNF project is accomplished as part of the project control system. A baseline schedule is established and agreed on as part of the MYPP process. Milestones defining expected performance and project deliverables as a function of the schedule are identified in the MYPP (currently termed the MMNP):

Major milestones that mark significant project events, such as design or acquisition of key project SSC, start of key operations, or completion of key documents are tracked by the DOE-RLSFD. Intermediate milestones that record progress toward completion of major milestones are tracked by WHC. Technical progress is tracked monthly by documenting milestone completion and progress relative to the baseline schedule. Progress is statused monthly for current-year milestones as part of the Site Management System (SMS) Reportand the SNF Project Monthly Program Review.

The integrated Project schedule identifies the inter-relationships of Project activities to enable an early identification of potential impacts to major milestones, when intermediate Project milestones are delayed or changed.

Monthly Site Management System reporting includes an assessment of potential impacts to future milestones. In addition, milestones beyond the current fiscal year are evaluated on an annual basis as part of the MYPP process. The Project Control System is defined in the Spent Nuclear Fuel Project Management Plan (WHC 1995a).

62. Section 4.8, Integration With Offsite Spent Nuclear Fuel Organizations:

Sections 4.8 through 4.11 have been reorganized. Replace these sections as shown in the following items.

Delete all paragraphs and replace with the following paragraphs:

\subsection{INTEGRATION WITHH THE OFFSITE SPENT NUCLEAR FUEL ORGANIZATIONS}

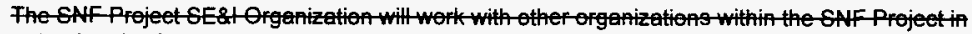
order that the-SNF Projectefforts remein integrated. The other SNF-Projectorgenizations that are required to work, to implement the gystemo engineering oes deseribe bove inetude the SNF

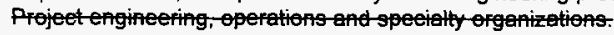

The DOE Office of Spent Nuclear Fuel Management (EM-67) currently is pursuing a systems engineering effort for all SNF in the DOE complex. These efforts will have impact on SNF Project 
systems engineering; and the SNFProject will integrate its systems engineering efforts with the DOE complex-wide efforts.

63. Section 4.9, Integration With the Hanford Site:

Sections 4.8 through 4.11 have been reorganized. Replace these sections as shown in the following items.

Delete all paragraphs and replace with the following paragraphs:

\section{9- NHEGRATHONWHFHN THE- GNF- SHBPROUEGTS}

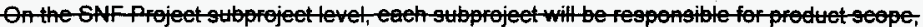
enfiguration, eost, sehedule, and peformene. Stbprojeets will bestruetured to facilitate the exeution of the SNFFroject aequigition strategy and the development prodtets on thesystems engineering product tree. The omposition of the subprojects shall be consistent with the SNF Project WBS. Subprojeets will follow theif product through the product developmenteyele into

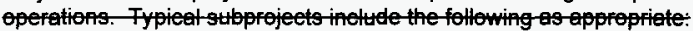

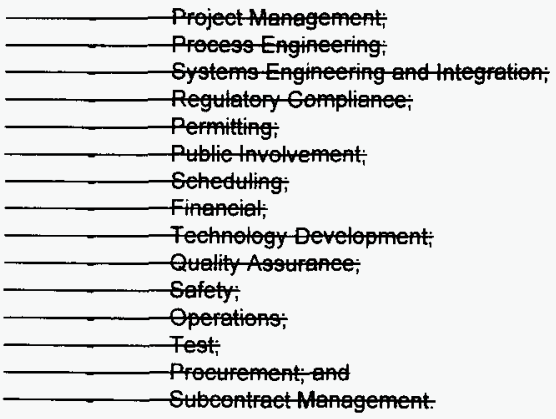

Staffing of the stoprojects may wan through time depending on the product and ito devetopment phere. Matrix and eontraetor support willbe inetuded.

The SAFPFojet SE\&HOrganization will integrate-gystems engineering fforto within the

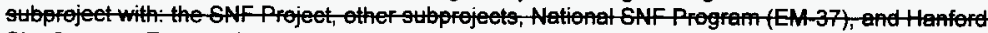
Site-systems Engine ring. Key to thig integration is the membership of the-SEstorganizetion staffon the suprojects. Interfecentrolandenfiguration manegementarekey proesses in the integretion of the-subprojects.

\subsection{INTEGRATION WITH THE HANFORD SITE}

The SNF Project is part of the Hanford Site cleanup, and receives ils top level guidance and direction from the site level. Site Systems Engineering has identified the necessity for the SNF Project through its functional breakdown. The SNF Rroject functional breakdown is a subset of the site functional breakdown. Because of this, SNF Rroject SE\&I wil have major continuous involvement with the Hanford Site Technical Integration organization to ensure that the SNF 
Project is performing systems engineering within the bounds of site efforts. Changes made by either the Hanford Site or the SNF Rroject will affect the other, and will require integration. The Hanford Site Technical Integration organization Will be the source of the SNF Project system specification.

The SNF Prolject SE\&I organization must won ${ }^{2}$ th other programs and projectSion the Hanford Site to integrate "Cleanup Hanford Site" effort erossithe site. In particular, SNFProject SE\& must integrate its systems engineering efforts whthose of other programs and projects. The majority of the extemal Integration effort Will focus on generation of Memorandauof Understanding (MOA), which are usedas ICDs.

64. Section 4.10, Integration Within Spent Nuclear Fuel Project Organizations:

Sections 4.8 through 4.11 have been reorganized. Replace these sections as shown in the following items.

Delete all paragraphs and replace with the following paragraphs:

\subsection{0- HFEgRATHONWHFHHANFORQ GFFE}

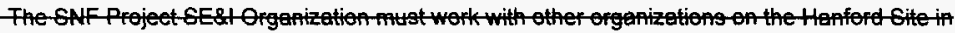
order integrate "Gleanup Hanford" efforts aerog the-site.

The SNF Projeet is part of the Hanford Site eleantp and reecives its toptevel guidenee and direetion form thesitelevel. Silte-Systems Engineering hes identified the need for the SAFF Projet

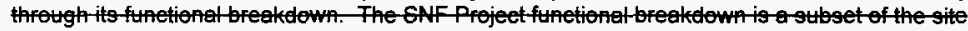
functional breakdown. Therefore, Henford Sitesygtems engineering efforts have preedenee

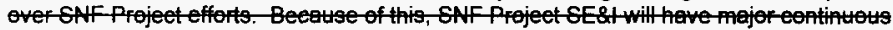
invelventent with Site Systems Engineering to enstre that the SNF Projeet is performing oystems

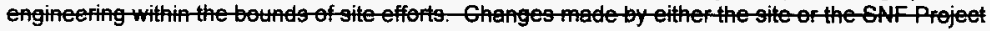
will affe the the and will requife integretion. The Henford-gitesystemsengineering will be the sotife of the SNF Project system speeifieation using provided the SNF-Project.

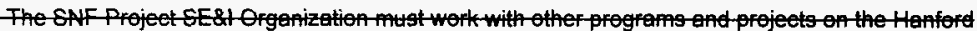
Site in order to integrate "Gleento Henfor" efforts-aeross the site. In particular, Systems Engineering must integrate its systems engineering efforts with thos of ther programs and

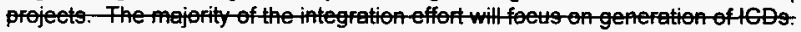

\subsection{INTEGRATION WITHIN SPENT NUCLEAR FUEL PROJECT ORGANIZATIONS}

The SNF Project SE\&l organization will work with other organizations within the SNF Project to ensure the SNF Project efforts remain integrated Other SNF Project organizations that are required to work to implement the systems engineering process described herein include the SNF Project engineering, operations, and supporting engineering organizations, such as Quality Assurance. 
65. Section 4.11, Integration Within the Spent Nuclear Fuel Subprojects:

Sections 4.8 through 4.11 have been reorganized. Replace these sections as shown in the following items:

Delete all paragraphs and replace with the following paragraphs:

\section{T1 INTEGRATHONWHTHOFFETTE GPENTNHGLEARFUELORGANZATHONS}

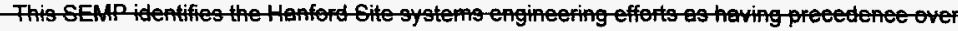
SAFF Proje effetts. The U.S. Deportment of Energy's (BOE) Offiee of Spent Nuted Fuet Menegement (EM-37) also is etrfently pursuing o systems engineering effertor allSNF in the

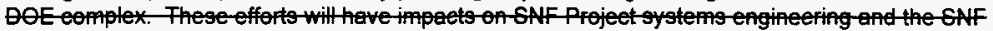
Project will integrate its gystems engineering efforts with the DOE-omplex-wide efforts. However,

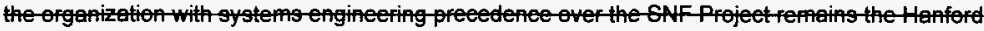
Site.

\subsection{INTEGRATION WITHINTHE SPENT NUCLEAR FUEL SUBPROJECTS}

At the SNF Project Subproject level, each Subproject will be responsible for product scope, configuration, cost, schedule, and performance. Subprojects will be structured to facilitate execution of the Project mission, and development of products on the systems engineering product tree. The Subproject Design Authority has the Technical responsibility and authority for the Subproject products. The Subprojects composition shall be consistent with the SNFProject WBS Subprojects will follow their product through the product development cycle into operations: Typical Subprojects include the following, as appropriate:

- Project Management,

- Process Engineering;

- Systems Engineering and Integration;

- Regulatory Compliance;

- Permitting;

- Public Involvement;

- Scheduling;

- Financial;

- Technology Development;

- Quality Assurance;

- Safety:

- Operations;

- Test;

- Procurement and

- Subcontract Management. 
Subproject staffing may vary throughout time, depending on the product and its development phase. Matrix and contractor support will be included.

The Project SE\&I organization will integrate systems engineering efforts within the Subproject with:

- The SNF Project;

- Other Subprojects;

- National SNFProgram(EM67), and

- Hanford Sitesystems Engineening.

Key to this integration is the membership of the SE\&lOrganization staff on the Subprojects. Interface control and configuration managementare key processes in Stibproject integration.

66. Section 4.12, Spent Nuclear Fuel Management Documents, Replace the paragraph with the following edited version:

For the SNF Project, management documents enable and supports the development of the integrated SNF Project technical baseline. The management documents that support SNF Project systems engineering technical practices are described in the SNF Project PMP (WHC 1995a).

67. Section 5.0, Glossary, and Section 6.0, References:

Switch Section 5.0, Glossary, with Section 6.0, References, so the new numbering system will be Section 5.0, References, and Section 6.0, Glossary.

68. Section 5.0, References:

This section has been revised extensively to match the new document. Replace the former WHCSD-SNF-SEMP-001, Rev. 0, reference section completely with the new WHC-SD-SEMP-001, Rev. 1, Section 5.0, References.

69. Section 6.0, Glossary:

This section has been revised extensively to match the new document. Replace the former WHC-SD-SNF-SEMP-001, Rev. 0, glossary section completely with the new WHC-SDSEMP-001, Rev. 1, Section 6.0, Glossary.

70. Appendices $\mathrm{A}, \mathrm{B}$, and $\mathrm{C}$ :

Add Appendices A, B, and C. 


\title{
Spent Nuclear Fuel Project Systems Engineering Management Plan
}

\author{
J. C. Homack
}

Westinghouse Hanford Company, Richland, WA 99352

U.S. Department of Energy Contract DE-AC06-87RL10930

ECN 191410

Org Code: $2 \mathrm{C300}$

B\&R Code: EW3135040

UC-510, Nuclear Waste Management

Charge Code: LB005

Total Pages: 57

Key Words: Systems Engineering Management Plan, Systems Engineering Process, Risk Management Process, Design Authority, Design Agent, and Documentation Responsibilities.

Abstract: The purpose of this document is to describe the systems engineering approach and methods that will be integrated with established WHC engineering practices. The methodology promotes and ensures sound management of the SNF Project. The scope of the document encompasses the efforts needed to manage the WHC implementation of systems engineering on the SNF Project including risk management process, design authority/design agent concept, and documentation responsibilities. This implementation applies to, and is tailored to the needs of the SNF Project and all its Subprojects, including all current and future Subprojects.

IRADEMARK DISCLAIMER. Reference herein to any specific comercial product, process, or service by trade name, trademark, manufacturer, or otherwise, does not necessarily constitute or imply its endorsement, recommendation, or favoring by the United States Government or any agency thereof or its contractors or subcontractors.

Printed in the United States of America. To obtain copies of this document, contact: WHC/BCS Document Control Services, P.O. Box 1970, Mailstop H6-08, Richland WA 99352, Phone (509) 372-2420; Fax (509) 376-4989.
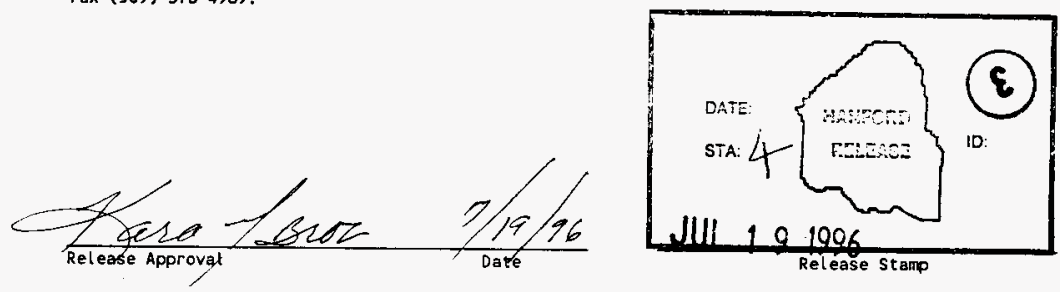

Approved for Public Release 


\section{RECORD OF REVISION}

$$
\begin{aligned}
& \text { (1) Document Number } \\
& \text { WHC-SD-SNF-SEMP- } \\
& 001
\end{aligned}
$$

(2) Title

Spent Nuclear Fuel Project Systems Engineering Management Plan

CHANGE CONTROL RECORD

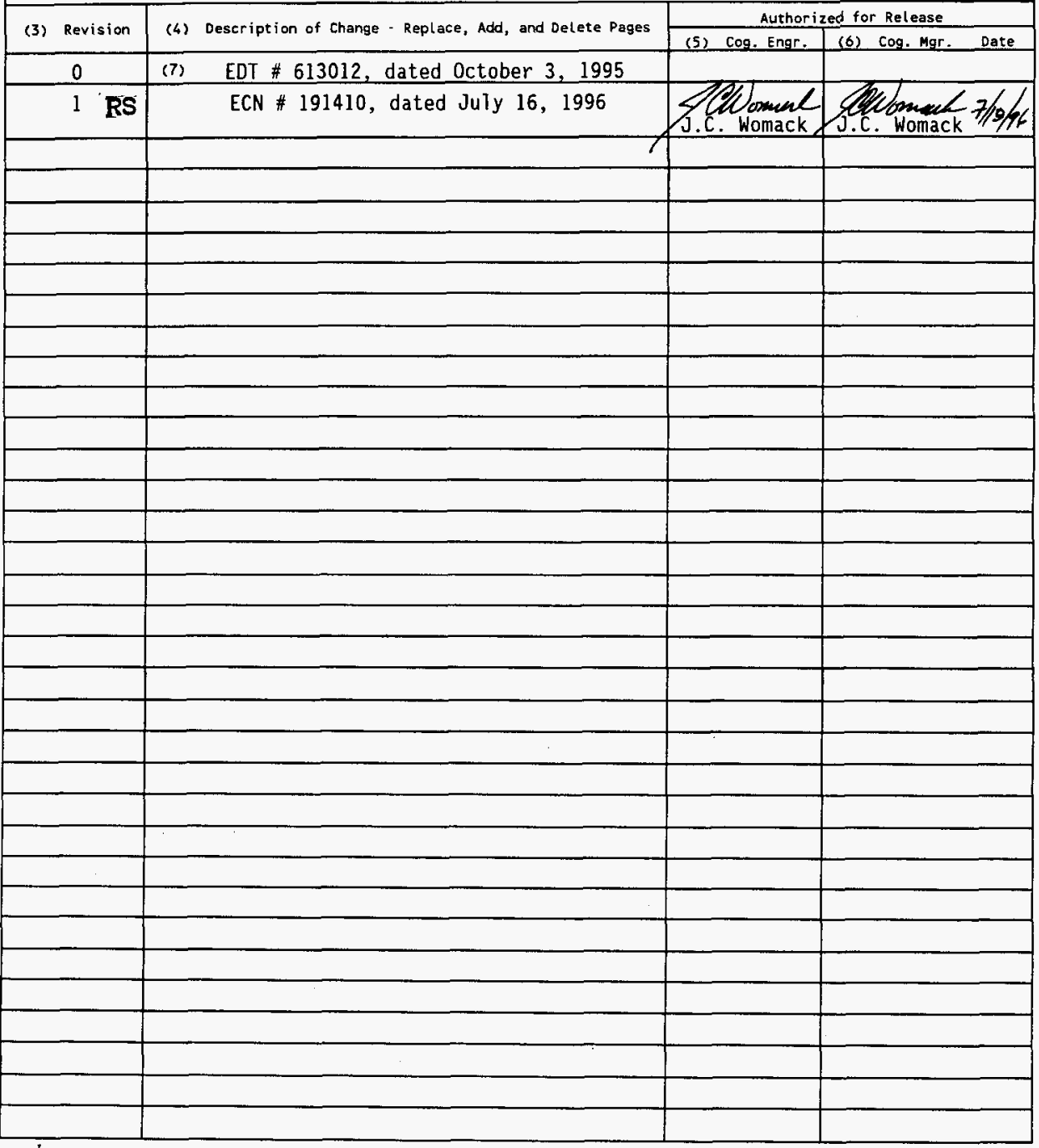


WHC-SD-SNF-SEMP-001, Rev. 1

\section{SPENT NUCLEAR FUEL PROJECT} SYSTEMS ENGINEERING MANAGEMENT PLAN

Westinghouse Hanford Company P.O. Box 1970

Richland, WA 99352

July 1996 


\section{TABLE OF CONTENTS}

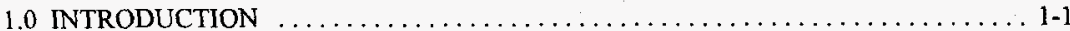

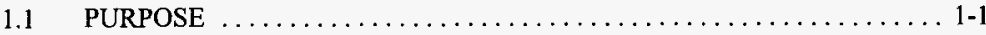

1.2 SCOPE AND CONTEXT $\ldots \ldots \ldots \ldots \ldots \ldots \ldots \ldots \ldots \ldots \ldots \ldots, 1$

2.0 SYSTEMS ENGINEERING ROLES AND RESPONSIBILITIES $\ldots \ldots \ldots \ldots \ldots \ldots$ 2-1

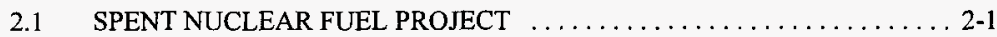

2.2 SPENT NUCLEAR FUEL SUBPROJECTS $\ldots \ldots \ldots \ldots \ldots \ldots \ldots \ldots \ldots \ldots \ldots$

2.3 SPENT NUCLEAR FUEL OPERATIONS $\ldots \ldots \ldots \ldots \ldots \ldots \ldots \ldots \ldots, 2-2$

3.0 SYSTEMS ENGINEERING TECHNICAL PRACTICES $\ldots \ldots \ldots \ldots \ldots \ldots$ 3-1

3.1 INTEGRATED SPENT NUCLEAR FUEL PROJECT ENGINEERING

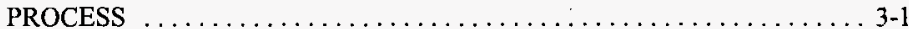

3.2 SYSTEMS ENGINEERING PROCESSES $\ldots \ldots \ldots \ldots \ldots \ldots \ldots \ldots \ldots \ldots \ldots \ldots, 2$

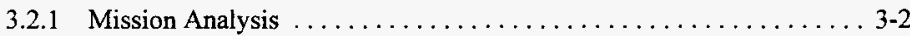

3.2.2 Functional Analysis $\ldots \ldots \ldots \ldots \ldots \ldots \ldots \ldots \ldots \ldots \ldots \ldots, 3-4$

3.2.3 Requirements Analysis $\ldots \ldots \ldots \ldots \ldots \ldots \ldots \ldots \ldots \ldots \ldots, 3-4$

3.2.4 Alternatives Analysis $\ldots \ldots \ldots \ldots \ldots \ldots \ldots \ldots \ldots \ldots \ldots, 3-5$

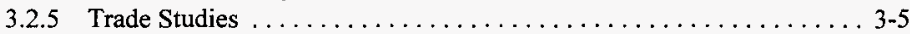

3.2.6 Requirements Specification ...................... 3-5

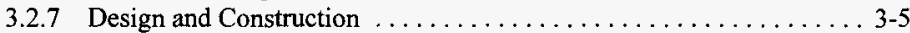

3.2 .8 Test $\ldots \ldots \ldots \ldots \ldots \ldots \ldots \ldots \ldots \ldots \ldots \ldots \ldots \ldots \ldots \ldots \ldots, 3-5$

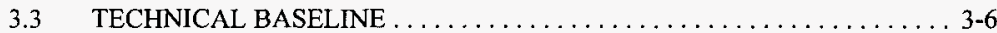

3.3.1 Functional Requirements Baseline $\ldots \ldots \ldots \ldots \ldots \ldots \ldots \ldots, 3.10$

3.3.2 Performance Requirements Baseline . . . . . . . . . . . . . . . . . 3-10

3.3.3 Design Requirements Baseline $\ldots . \ldots \ldots \ldots \ldots \ldots \ldots \ldots \ldots . . \ldots$ 3-10

3.3.4 Design Configuration Baseline $\ldots \ldots \ldots \ldots \ldots \ldots \ldots \ldots \ldots, 3-10$

3.3.5 As-Built Configuration Baseline $\ldots \ldots \ldots \ldots \ldots \ldots \ldots \ldots \ldots, 3-10$

3.3.6 Operational Baseline ........................... 3-11

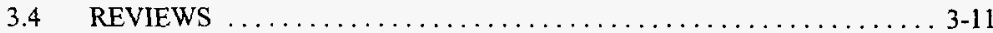

3.4.1 System Requirements Review ..................... 3-11

3.4.2 Conceptual Design Review ....................... 3-12

3.4.3 Preliminary Design Review ....................... 3-12

3.4.4 Definitive Design Review . . . . . . . . . . . . . . . . . . . . . . . 3-12

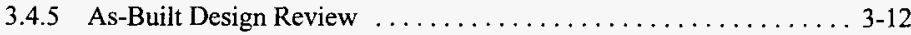

3.4.6 Operational Readiness Review $\ldots \ldots \ldots \ldots \ldots \ldots \ldots \ldots \ldots$. 3-12

3.5 SYSTEMS ENGINEERING TECHNICAL DOCUMENTATION $\ldots \ldots \ldots .3-13$

3.6 REQUIREMENTS DOCUMENTATION . . . . . . . . . . . . . . . 3-13

3.6.1 Spent Nuclear Fuel Project Specification $\ldots \ldots \ldots \ldots \ldots \ldots \ldots .3-13$

3.6.2 Functions and Requirements Documentation .............. 3-13

3.6.3 Requirements Specification ...................... 3-13

3.6.4 Baseline Documentation and Database $\ldots \ldots \ldots \ldots \ldots \ldots \ldots . . \ldots \ldots$ 
4.0 SYSTEMS ENGINEERING MANAGEMENT PRACTICES $\ldots \ldots \ldots \ldots \ldots \ldots .4 .1$

4.1 FUNCTIONS AND REQUIREMENTS MANAGEMENT $\ldots \ldots \ldots \ldots \ldots .4-1$

4.2 CONFIGURATION MANAGEMENT $\ldots \ldots \ldots \ldots \ldots \ldots \ldots \ldots \ldots, 4$

4.3 TECHNICAL INTERFACE CONTROL $\ldots \ldots \ldots \ldots \ldots \ldots \ldots \ldots \ldots, 4-1$

4.4 RISK MANAGEMENT $\ldots \ldots \ldots \ldots \ldots \ldots \ldots \ldots \ldots \ldots \ldots \ldots, 4-1$

4.5 WORK BREAKDOWN STRUCTURE $\ldots \ldots \ldots \ldots \ldots \ldots, \ldots \ldots \ldots, 4-2$

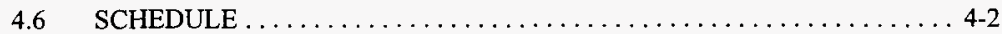

4.7 PERFORMANCE MEASUREMENT $\ldots \ldots \ldots \ldots \ldots \ldots \ldots \ldots \ldots \ldots 4-3$

4.8 INTEGRATION WITH OFFSITE SPENT NUCLEAR FUEL

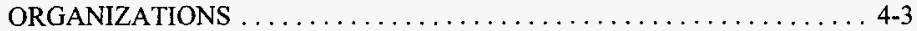

4.9 INTEGRATION WITH THE HANFORD SITE $\ldots \ldots \ldots \ldots \ldots \ldots \ldots .4-3$

4.10 INTEGRATION WITHIN SPENT NUCLEAR FUEL PROJECT ORGANIZATIONS . ............................ 4-4

4.11 INTEGRATION WITHIN THE SPENT NUCLEAR FUEL SUBPROJECTS . . ......................... 4 4

4.12 SPENT NUCLEAR FUEL PROJECT MANAGEMENT DOCUMENTS . . . 4 4-5

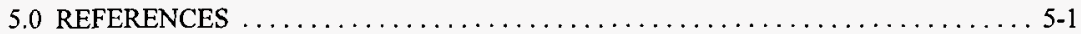

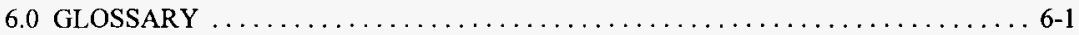

\section{APPENDICES}

A. DOCUMENTATION RESPONSIBILITIES $\ldots \ldots \ldots \ldots \ldots \ldots \ldots \ldots$ A-1

B. SPENT NUCLEAR FUEL PROJECT DESIGN AUTHORITY/DESIGN AGENT PROCESS $\ldots \ldots \ldots \ldots \ldots \ldots \ldots \ldots \ldots \ldots \ldots \ldots \ldots \ldots \ldots \ldots \ldots \ldots \ldots \ldots \ldots \ldots, 1$

C. RISK MANAGEMENT IN THE SPENT NUCLEAR FUEL PROJECT $\ldots \ldots \ldots \ldots$ C-1

\section{FIGURES}

1-1. Spent Nuclear Fuel Project Systems Engineering Management Plan Context . . . . . 1-3

3-1. Spent Nuclear Fuel Project Integrated Engineering Process . . . . . . . . . . . 3-3

3-2. Integrated Baseline Development ........................... 3-7

3-3. Spent Nuclear Fuel Project Integrated Engineering Process $\ldots \ldots \ldots \ldots \ldots \ldots \ldots$ 3-9 


\section{TABLES}

3-1. Spent Nuclear Fuel Project Technical Baselines

\section{ACRONYMS}

$\begin{array}{ll}\text { ADR } & \text { As-Built Design Review } \\ \text { BMS } & \text { Baseline Management System } \\ \text { BSD } & \text { Baseline System Description } \\ \text { CMP } & \text { Configuration Management Plan } \\ \text { DDR } & \text { Definitive Design Review } \\ \text { DOE } & \text { U.S. Department of Energy } \\ \text { DOE-RL } & \text { U.S. Department of Energy - Richland Operations Office } \\ \text { DOE-RL/SFD } & \text { U.S. Department of Energy - Richland Operations Office/Spent Fuels } \\ & \text { Division } \\ \text { FDC } & \text { Functional Design Criteria } \\ \text { FHO } & \text { Fuel Handling Operations } \\ \text { F\&R } & \text { Functions and Requirements } \\ \text { ICD } & \text { Interface Control Document } \\ \text { ICWG } & \text { Interface Control Working Group } \\ \text { MOU } & \text { Memorandum of Understanding } \\ \text { MYPP } & \text { Multi-Year Program Plan } \\ \text { MYWP } & \text { Multi-Year Work Plan } \\ \text { NSNFP } & \text { National Spent Nuclear Fuel Program (DOE-HQ/EM-67) } \\ \text { ORR } & \text { Operational Readiness Review } \\ \text { PDR } & \text { Preliminary Design Review } \\ \text { PFD } & \text { Process Flow Diagram } \\ \text { PMP } & \text { Project Management Plan } \\ \text { PSAR } & \text { Preliminary Safety Analysis Report } \\ \text { RLID } & \text { U.S. Department of Energy-Richland Operations Offices, Implementing } \\ \text { RLPD } & \text { Directive } \\ \text { SAR } & \text { U.S. Department of Energy-Richland Operations Office, Policy Directive } \\ & \text { Safety Analysis Report } \\ \end{array}$




\section{ACRONYMS}

$\begin{array}{ll}\text { SDR } & \text { System Design Review } \\ \text { SE\&I } & \text { Systems Engineering and Integration } \\ \text { SEMP } & \text { Systems Engineering Management Plan } \\ \text { SMS } & \text { Site Management System } \\ \text { SNF } & \text { Spent Nuclear Fuel } \\ \text { S/RIDs } & \text { Standards/Requirements Identification Documents } \\ \text { SRR } & \text { System Requirements Review } \\ \text { SSC } & \text { Structure, System, and Component } \\ \text { T\&E } & \text { Test and Evaluation } \\ \text { TPM } & \text { Technical Performance Measurement } \\ \text { V\&V } & \text { Verification and Validation } \\ \text { WBS } & \text { Work Breakdown Structure } \\ \text { WHC } & \text { Westinghouse Hanford Company }\end{array}$




\subsection{INTRODUCTION}

\subsection{PURPOSE}

The strategy to accomplish the Spent Nuclear Fuel (SNF) Project mission and objectives includes the implementation of systems engineering. Systems engineering is a disciplined approach to managing the project from top to bottom and from cradle to grave, to ensure that the project is doing the "correct" things.

This SNF Project Systems Engineering Management Plan (SEMP) describes the systems engineering approach, methods and processes that are being integrated with established engineering practices to enhance the engineering management of the Project. It is not a complete treatise on the systems engineering discipline. The SEMP format and content have been tailored to meet specific needs of the SNF Project.

This SEMP satisfies the requirements set forth in the following documents:

- Hanford Site Systems Engineering Policy, U.S. Department of Energy (DOE) RLPD 430.1 (RL 1996a), which directs that systems engineering be implemented at the Hanford Site, consistent with the Systems Engineering Criteria Document and Implementing Directive, DOE RLID 430.1 (RL 1996b);

- Project Management, WHC-CM-6-2 (WHC 1996a), states that where a SEMP is appropriate, it should be prepared in accordance with the Project Management System, DOE Order 4700.1 (DOE 1987);

- $\quad$ Project Management System, DOE Order 4700.1, Chapter III, which states that the systems engineering management process normally is controlled by adherence to a SEMP, prepared and maintained at the project level (Note that DOE Order 4700.1 will be phased out and cancelled after meeting implementation conditions of Life Cycle Assessment Management, DOE Order 430.1 (DOE 1995). Currently, DOE Order 4700.1 is a compliance document and DOE Order 430.1 is not);

- Spent Nuclear Fuel Project Management Plan, WHC-SD-SNF-PMP-011 (WHC 1995a), which directs that a SEMP be developed for the SNF Project; and

- Systems Engineering Criteria Document and Implementing Directive, DOE RLID 430.1 , which provides direction on the implementation of systems engineering at the Hanford Site, based on DOE Order 430.1.

\subsection{SCOPE AND CONTEXT}

This SEMP encompasses the efforts necessary to manage systems engineering implementation for the SNF Project. This implementation applies, and is tailored to, SNF Project 
needs, all its current and future Subprojects, and sub-tier activities. Major physical activities supporting accomplishment of the SNF Project mission are referred to as Subprojects. Each Subproject is an organizational entity, managed as a project responsible for product design, development, fabrication, and testing. This includes project scope, configuration, cost, schedule, and performance. Subproject participation is by team, involving all appropriate disciplines, including operations. Each Subproject will prepare a management plan or work plan. Each subproject may prepare a SEMP. A Subproject SEMP is not necessary if the SNF Project SEMP is adequate, as tailored in the subproject management plan. Subproject size is an important factor in determining whether a separate SEMP is necessary.

This SEMP is intended for application to the design, development, fabrication, construction, test and startup of the Spent Nuclear Fuel Path Forward Subprojects leading to SNF Operations. After SNF Operations assumes responsibility for the system, a modified process, tailored to maintenance and operations is necessary. This process is not included in this SEMP. The K Basin engineering process is consistent with processes in this SEMP.

Figure 1-1 depicts the relationship of this SEMP to other systems engineering guidance documents. The SNF Project SEMP content is derived from the Site Systems Engineering, Site Systems Engineering Management Plan, (WHC 1996b), DOE RLID 430.1 (RL 1996b), and the Spent Nuclear Fuel Project Management Plan (WHC-SD-SNF-PMP-011) (WHC 1995a). All other systems engineering process interfaces will be through these documents. Because the transition from DOE Order 430.1 is not complete, this SEMP has maintained its consistency with DOE Order 4700.1 , as well. 
WHC-SD-SNF-SEMP-001, Rev. 1

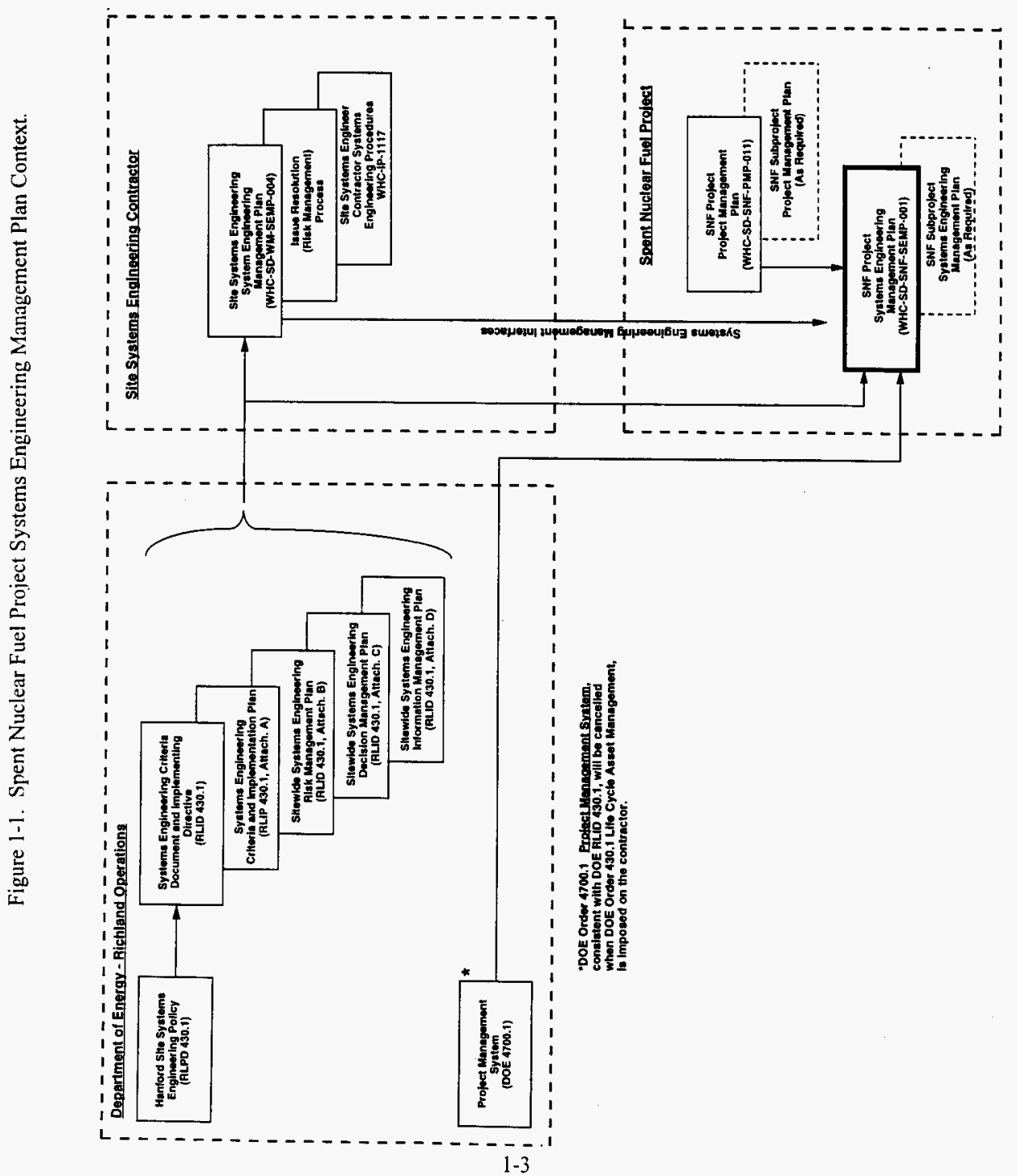


WHC-SD-SNF-SEMP-001, Rev. 1

\subsection{SYSTEMS ENGINEERING ROLES AND RESPONSIBILITIES}

\subsection{SPENT NUCLEAR FUEL PROJECT}

Project organization roles and responsibilities are defined in the Spent Nuclear Fuel Project Management Plan (PMP), WHC-SD-SNF-PMP-011 (WHC 1995a). This section of the SEMP identifies, and is limited to, the roles and responsibilities associated with implementation of Systems Engineering in the Project and Subprojects. Documentation responsibilities related to SNF Project and SNF Subprojects are defined in Appendix A, which may be revised when the information is superseded by higher level Project documentation.

Successful implementation of systems engineering is dependent on the active involvement of all SNF Project and Subproject organizations in the systems engineering processes, documents and procedures, as defined in Sections 3.0 and 4.0. The Systems Engineering and Integration (SE\&I) organization provides systems engineering core competency, consistency between Subprojects, and maintenance of the Project technical baseline. In addition, the SE\&I organization may facilitate development and upkeep of systems engineering processes, databases, and documentation products throughout the SNF Project life.

\subsection{SPENT NUCLEAR FUEL SUBPROJECTS}

A new Design Authority/Design Agent concept was established as part of the design process re-engineering. This process focusses Technical responsibility and authority, including implementation of systems engineering and integration activities, with the Subproject Design Authorities. This process, along with the Design Authority and Design Agent roles and responsibilities, has been implemented in the SNF Project, as described in Standard Engineering Practices, WHC-CM-6-1, Interim Design Authority/Design Agent Engineering Process Requirements, EP 5.9 (WHC 1996c). Appendix B presents a description of this implementation.

Each Subproject is responsible for product scope, configuration, cost, schedule, and performance. Subproject Design Authorities are responsible for implementation of systems engineering processes and delivery of systems engineering products for their Subprojects to tie into SNF Operations. The SNF Project SE\&I organization may integrate the Subproject systems engineering efforts with those of the Project, other Subprojects, the National SNF Program (EM-67), and the Hanford Site Systems Engineering. The SE\&I organization will support development and maintenance of Subproject processes and documents.

Subproject roles and responsibilities change throughout the Project life-cycle. Each Subproject ensures expected operation of the Structure, System, and/or Component (SSC), prior to turn-over to SNF Operations. After the Subproject Functions and Requirements (F\&Rs)/Function Design Criteria (FDC)/specifications are determined, the role of the SE\&I organization will shift to supporting the verification and validation (V\&V) that requirements are 
being met, coordinating change management, and maintaining interfaces with other Subprojects. Change management includes risk, decision, and issues management.

\subsection{SPENT NUCLEAR FUEL OPERATIONS}

The SNF Operations is currently comprised of $\mathrm{K}$ Basins and Fuel Handling Operations (FHO). The K Basins focuses on existing facilities and the FHO interfaces with Path Forward activities to ensure that all systems are in place, from the beginning of fuel retrieval to interim fuel storage in the Hanford Site 200 East Area.

The SE\&I will continue to ensure that the SNF Project Technical Baseline is maintained through coordination of change management and interface control processes. The SNF

Operations is responsible for operating and maintaining SNF facilities within the approved safety analysis, Standards/Requirements Identification Documents (S/RIDs), and operational design criteria; and for maintaining the physical configuration control. 


\subsection{SYSTEMS ENGINEERING TECHNICAL PRACTICES}

\subsection{INTEGRATED SPENT NUCLEAR FUEL PROJECT ENGINEERING PROCESS}

The SNF Project integrated engineering process includes the systems engineering processes by which the SNF Project defines its mission and determines the functions it needs to perform; the requirements it must meet; the SSC, which best meet these requirements; and the verification methods to be used to ensure that the design and operations requirements are met. This integrated process includes Subproject design, development, analysis, fabrication, and testing leading to operations. Figure 3-1 illustrates the basic integrated SNF Project engineering process. The basic process as shown in this figure is streamlined. Actual implementation requires feedback and interaction loops allowing for refinements, decision making, and validation at each step. Between conceptual design initiation and operations start, systems engineering activities focus on SNF Project integration, project optimization, requirements verification and validation, and change management.

The integrated engineering process will be implemented through the use of the Westinghouse Hanford Company (WHC) Controlled Manual system and the systems. engineering processes in the Hanford Site Systems Engineering Manual, WHC-IP-1117 (WHC 1995b). The Hanford Site Systems Engineering Manual procedures are used to implement the process, unless the procedures are defined specifically in this SEMP.

System integration activities continuing throughout the engineering process life include:

- Parametric Analysis;

- Trade Studies;

- $\quad$ Alternative Analysis;

- Decision Analysis;

- $\quad$ Risk Analysis and Management;

- Requirements Verification and Validation;

- Technical Performance Measurement;

- Integrated Schedule Analysis;

- Life-Cycle Cost Analysis;

- $\quad$ Asset Life-Cycle Plans;

- Specialty Engineering Integration;

- Configuration Management;

- Change Management; 
- Interface Management and Control;

- Issue Management;

- Baseline Integration;

- Systems Engineering Integration (Subprojects, Hanford Site, and DOE EM-67);

- $\quad$ Systems Test and Evaluation;

- Standards/Requirements Identification Documentation (S/RIDs); and

- $\quad$ Safety Analysis Report (SAR) Requirements Management.

These activities are primarily managed by other than the SE\&I organization, although they may be supported by the SNF Project SE\&I organization.

\subsection{SYSTEMS ENGINEERING PROCESSES}

Specific processes that make up the systems engineering portions of the integrated engineering process are described in Sections 3.2.1 through 3.2.8. The processes not defined in these sections are described in Standard Engineering Practices, WHC-CM-6-1 (WHC 1996c). The Hanford Site Systems Engineering Manual, WHC-IP-1117 (WHC 1995b), provides a description of the specific procedures.

\subsubsection{Mission Analysis}

Mission analysis is the first step in the overall process. The analysis defines the Project or Subproject problem, the initial unacceptable conditions, the acceptable final conditions, external constraints and interfaces, and resources required. It also establishes the basis for developing a system to resolve the Project or Subproject problem so that the mission can be accomplished. Thus, the mission analysis defines, scopes, and bounds the Project or Subproject. The initial SNF Project mission analysis was conducted in 1994. This is documented in Spent Nuclear Fuel Project Mission Analysis Report, WHC-EP-0790 (WHC 1994a). Mission analysis continues through the life cycle to address items such as DOE redirection, cost and schedule performance, etc. Mission analyses for Subprojects are not required, but may be conducted if the Subproject defines them in Subproject management plans. 
Figure 3-1. Spent Nuclear Fuel Project Integrated Engineering Process.

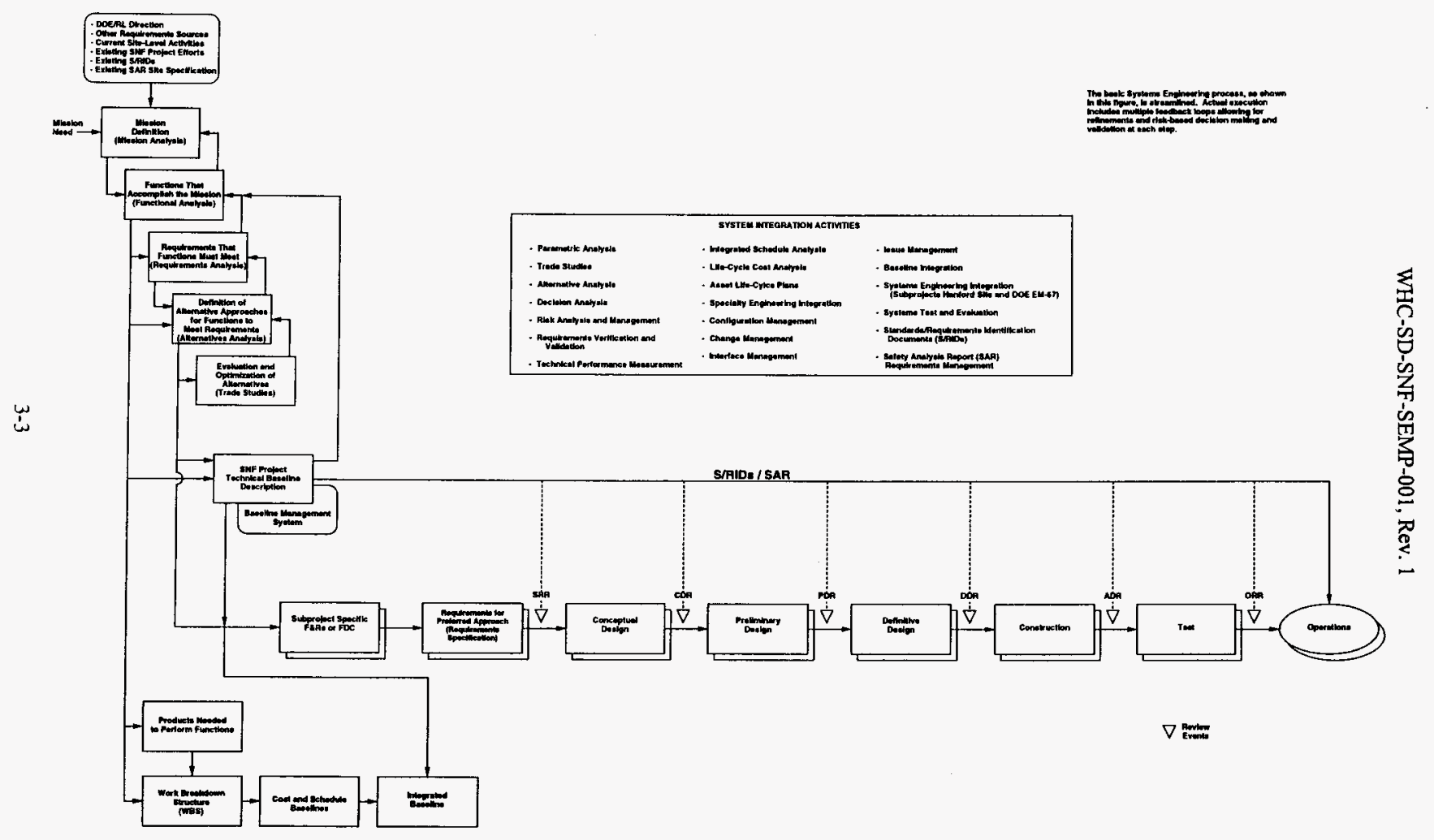




\subsubsection{Functional Analysis}

Functional analysis identifies the functions that must be performed to accomplish the mission. These functions are then developed at increasingly greater levels of detail to provide an increasingly explicit mission depiction. For the SNF Project, these greater levels of detail become the functions of the Subprojects and SNF Operations. The SNF Project Process Flow Diagrams (PFD) in the Spent Nuclear Fuel Project Process Flow Diagram Summary, H-2825867 (WHC 1996d), and Spent Nuclear Fuel Project Level 0 Process Flow Diagram, H-2825868 (WHC 1996e), were produced to support the engineering process, and are a further development of the functions directly associated with chemical and nuclear processes.

\subsubsection{Requirements Analysis}

Requirements analysis identifies the requirements associated with each function. Requirements define how well a function must be performed. Requirements allocated to Subproject functions become that Subproject's requirements. This analysis uses a top-down allocation of requirements from the primary sources of law, regulations, and DOE direction and orders, as well as requirements derived from studies, analyses, and tests.

Functional requirements are derived by expanding functions until they become detailed enough to define the requirements necessary to perform a function. After quantitative values are defined for these requirements, the requirements become performance requirements. After the functions have been decomposed into functional performance requirements, the requirements can be allocated to SSC. Specifications are associated with SSC.

The S/RID process identifies and validates environmental, safety, and health requirements for existing and future Hazard Category 2 facilities of the SNF Project. The S/RID process identifies standards, regulations, orders, and laws, as well as, "Best Commercial Practices" to establish a minimum set of requirements that are necessary and sufficient to implement a sound environmental, safety, and health posture. These requirements are validated and approved by DOE-RL.

Other requirements sources include design studies; interfaces; analyses (including safety analyses with resulting Operating Safety Requirements and Technical Safety Requirements); trade studies; conceptual design; and verifications associated with a SSC. Safety analyses that result in the Project SAR are examples of sources of derived requirements. These derived requirements must be integrated into the requirements of the Subprojects and/or Project after the initial requirements analyses. The definition of these requirements throughout the design process results in the need for update, addition, revision, and modification of the requirements database and documentation. The S/RIDs and derived systems engineering requirements are integrated and maintained. Another source of SNF Project derived requirements are the studies that produce the U.S. Nuclear Regulatory Commission (NRC) equivalency requirements, as documented in the Spent Nuclear Fuel Project Path Forward, Additional Nuclear Regulatory Commission Requirements, WHC-SD-SNF-DB-003, WHC 1995c. 
During facility operation, S/RIDs and SAR are used to document the operational requirements. The S/RIDs are also created for Hazard Category 2 facilities associated with the SNF Subprojects. The SAR, along with S/RIDs, provides a source of derived safety requirements. Identification of the specific requirements is included in the Subproject $F \& R$ or FDC document, and the Subproject requirements specification, as necessary and appropriate.

The SNF Operations F\&Rs are the responsibility of the SNF Project FHO Organization.

\subsubsection{Alternatives Analysis}

The alternatives analysis identifies alternative solutions for SSC configurations (architectures) for functions that meet the requirements of those functions. These analyses are conducted at Project and Subproject levels, as appropriate, down to and including components.

\subsubsection{Trade Studies}

Trade studies are a portion of the engineering process of comparing or trading the strengths and weaknesses of alternative approaches or attributes. Trade studies are the basis for selection of alternatives. The trade studies shall include decision criteria that incorporate mission objectives and stakeholder values, and that will result in selection of solutions that satisfy requirements. These trade studies are performed at both the Project and Subproject levels.

\subsubsection{Requirements Specification}

A requirements specification is a document that is prepared to support development and/or acquisition of a SSC. The requirements specification can be used for SSC development by WHC, or to support procurement from a vendor. These documents are further discussed in Section 3.6. These documents are the responsibility of the Subproject Design Authorities.

\subsubsection{Design and Construction}

Design and construction processes associated with the SNF integrated engineering process are defined in Standard Engineering Practices, WHC-CM-6-1 (WHC 1996c) and Project Management, WHC-CM-6-2 (WHC 1996a), and are not repeated in this document.

\subsubsection{Test}

Testing will occur throughout the facility and system life cycle, including that testing that is required to support design, safety analyses, operational readiness, and post start-up process optimization. This life-cycle testing is described in the Spent Nuclear Fuel Project Integrated Testing Strategy, WHC-SD-SNF-CM-004 (PNNL 1996). Final testing includes acceptance 
testing, conducted by the Subproject to verify that the system has met design requirements; and operability testing, conducted by appropriate operations organizations to ensure that operations requirements have been met. The acceptance and operability testing will be addressed in the start-up plan currently being developed by the SNF Project FHO.

\subsection{TECHNICAL BASELINE}

The SNF Project technical baseline is the documented body of technical information associated with the people, products, and processes required to accomplish the SNF Project mission. The SNF Project technical, schedule, and cost baselines comprise the integrated SNF Project baseline. Figure 3-2 depicts the relationships of these baselines, and shows the progression from functions and products, to the Work Breakdown Structure (WBS), to the schedule, and in turn, the cost baselines. The SNF Project organizational structure is designed to support WBS performance. The SNF Project organization is presented in the currently published SNF Project organization charts.

Because the SNF Project is comprised of Subprojects that are at various levels of maturity and development, the technical baseline is composed of the Subproject technical baselines that are also at various development stages. These progressively more-detailed technical baselines have different names. Table 3-1 describes the progression of technical baselines. These baselines are under configuration control after initial approval. Figure 3-3 illustrates the relationship of these baselines to the integrated engineering process. The technical baseline contents are primarily documents in the SNF Project that result from other engineering activities. The baseline development process presented reflects the SNF Project's own needs. The SNF Project baseline development integrates with the Hanford Site baseline development. The Technical Baseline Description establishes the requirements baseline down to the Subprojects. Subproject details are the prerogative of the Subprojects. Only the Functional Requirements technical baseline shall be developed at the SNF Project and Subproject level. Subproject and operations organizations develop all other technical baselines.

$\mathrm{K}$ Basins organization was in progress at the time the SNF Project was established and integrated into the SNF Project. At that time, K Basins organization was integrated into the SNF Project to continue $\mathrm{K}$ Basins maintenance and operations in a safe and environmentally compliant manner during development of the other SNF Project portions. As such, K Basins organization has an established As-Built Configuration Technical Baseline, Configuration Management Plan, Operational S/RIDs, and SAR, that serve as a basis for risk management. For these reasons, $\mathrm{K}$ Basins organization does not need the steps leading to the As-Built Configuration Baseline. 
WHC-SD-SNF-SEMP-001, Rev. 1

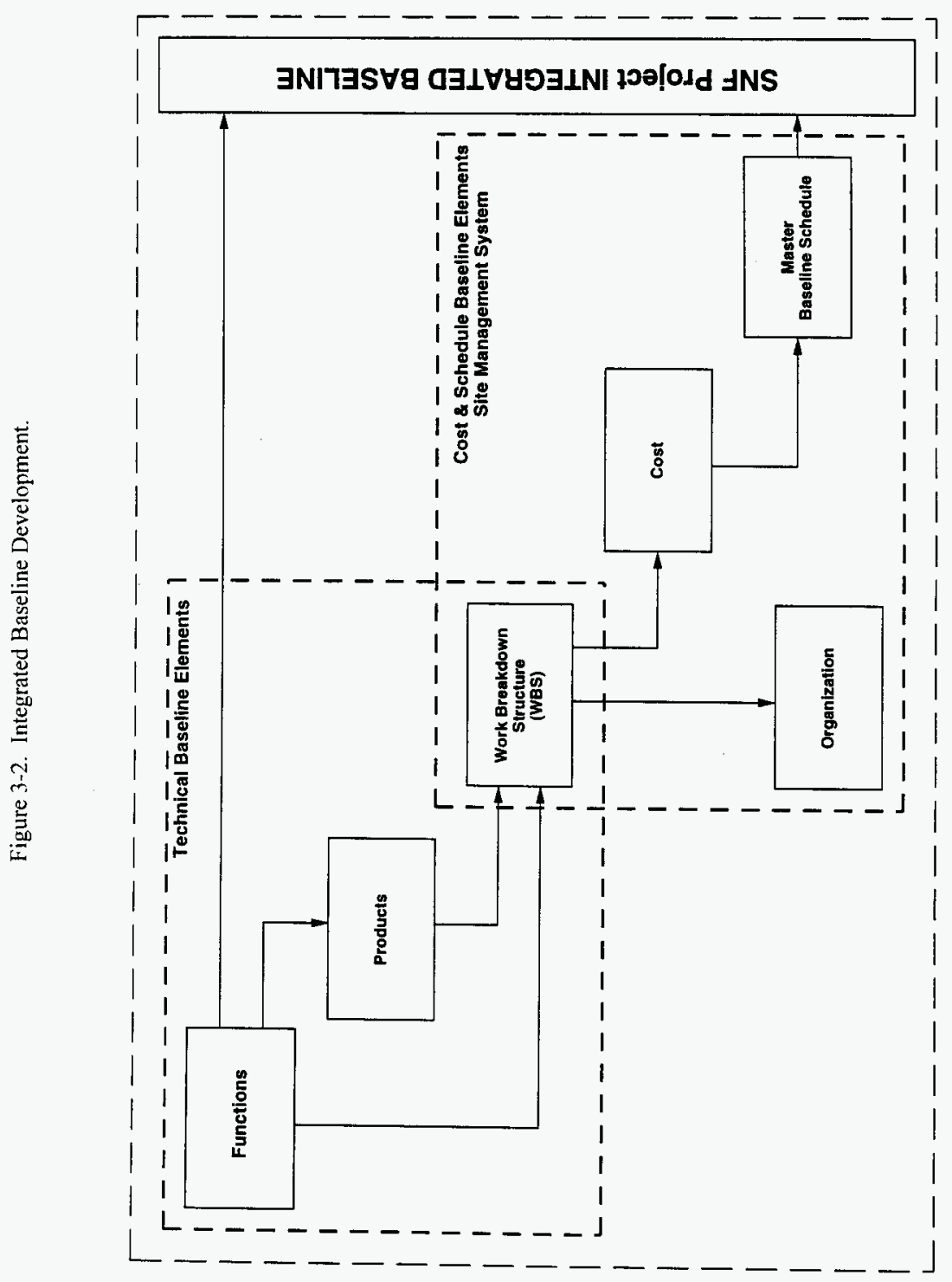


Table 3-1 SNF Project Technical Baselines.

\begin{tabular}{|c|c|}
\hline $\begin{array}{c}\text { Technical } \\
\text { Baseline Title }\end{array}$ & Baseline Components \\
\hline $\begin{array}{l}\text { Functional } \\
\text { Requirements } \\
\text { Baseline }\end{array}$ & $\begin{array}{l}\text { Project Mission Analysis Report; } \\
\text { Project Baseline Concept Description (BCD); } \\
\text { Project Systems Engineering Process Results (Issues, Assumptions, Trade } \\
\quad \text { Studies, Risks, and Decisions); } \\
\text { Interface Control Documents (ICD) Scope Sheets (Major Physical } \\
\quad \text { Interfaces); } \\
\text { Project Functions and Requirements; and } \\
\text { Subproject F\&R or FDC. }\end{array}$ \\
\hline \begin{tabular}{|l} 
Performance \\
Requirements \\
Baseline
\end{tabular} & $\begin{array}{l}\text { Subproject F\&R and Requirements Specifications ; } \\
\text { ICD Scope Sheets; } \\
\text { Subproject Conceptual Design Report; and } \\
\text { Preliminary Safety Analysis Report (PSAR). }\end{array}$ \\
\hline $\begin{array}{l}\text { Design } \\
\text { Requirements } \\
\text { Baseline }\end{array}$ & $\begin{array}{l}\text { Design Specifications; } \\
\text { ICDs; } \\
\text { Preliminary (Title I) Design Packages; and } \\
\text { Preliminary Facility* S/RID. } \\
\end{array}$ \\
\hline $\begin{array}{l}\text { Design } \\
\text { Configuration } \\
\text { Baseline }\end{array}$ & $\begin{array}{l}\text { Construction Specifications; } \\
\text { Test Plans and Procedures; } \\
\text { Definitive (Title II) Design Packages; and } \\
\text { Facility* S/RID. } \\
\end{array}$ \\
\hline $\begin{array}{l}\text { As-Built } \\
\text { Configuration } \\
\text { Baseline }\end{array}$ & $\begin{array}{l}\text { Construction Specification Revisions; } \\
\text { Test Reports; and } \\
\text { As-Built (Title III) Design Packages. }\end{array}$ \\
\hline $\begin{array}{l}\text { Operational } \\
\text { Baseline }\end{array}$ & $\begin{array}{l}\text { Operational Procedures (Updated); } \\
\text { Safety Analysis Report (SAR); } \\
\text { Final Facility" S/RID; and } \\
\text { Physical Configuration Design and Description. }\end{array}$ \\
\hline
\end{tabular}

The S/RID is prepared for Hazard Category 2 facilities. 
WHC-SD-SNF-SEMP-001, Rev. 1

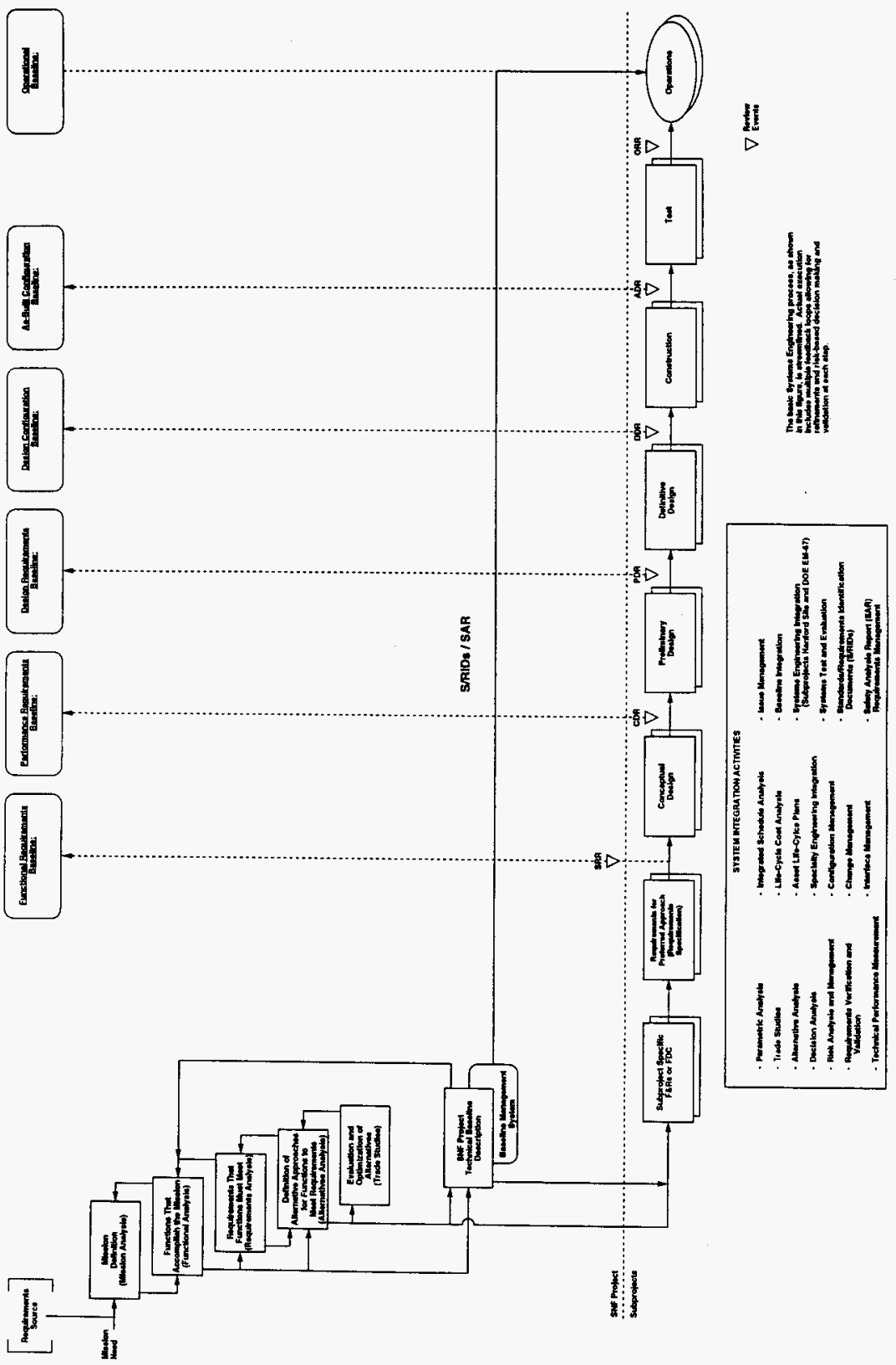




\subsubsection{Functional Requirements Baseline}

The SNF Project-level Functional Requirements Baseline describes the SNF Project approach, top-level requirements and constraints, and top-level functional and architectural features. This baseline provides the necessary details for start of Subproject conceptual design. The Functional Requirements Baseline has its basis in the Systems Engineering Functions and Requirements for the Hanford Cleanup Mission: First Issue, WHC-EP-0722 (WHC 1994b). This baseline is developed by analyzing the contents of these site baselines and applying the information to the SNF Project. This is documented in the Project Technical Baseline Description. The SNF Project Functional Requirements Baseline is a component of the Hanford Site Performance Baseline. The SNF Project SE\&I organization develops this baseline at the SNF Project level, and Subproject teams further develop this baseline at the Subproject levels.

\subsubsection{Performance Requirements Baseline}

The contents of each Subproject baseline represent the performance requirements and SSC configurations (architectures) chosen to accomplish the SNF Project mission. The Performance Requirements Baseline forms the basis for initiating preliminary design.

\subsubsection{Design Requirements Baseline}

The contents of each baseline expand on the technical requirements allocated to each Subproject, delineate more-detailed derived requirements, and add technical requirements that reflect design configuration (architecture) decisions and preliminary design. The Design Requirements Baseline becomes the basis for definitive design.

\subsubsection{Design Configuration Baseline}

The Design Configuration Baseline contents show the progress of the Subprojects in refining the design and developing the "build-to" design packages. The Design Configuration Baseline forms the basis for the beginning of construction and testing.

\subsubsection{As-Built Configuration Baseline}

The As-Built Configuration Baseline documents the completed construction, and validates the operational basis. The As-Built Configuration Baseline is the technical basis for the start of operations. Constituents of the As-Built Configuration Baseline are components of Site As-Built Baselines. 


\subsubsection{Operational Baseline}

The Operational Baseline includes updated operational procedures, SAR, final facility S/RIDs, and physical configuration design and description. Operational Baseline items are the basis for continuing operations, and will be used as the deactivation activities starting point.

\subsection{REVIEWS}

This section describes SNF Project and Subproject reviews. The SNF Project will adapt a review process to reflect the SNF Project's own needs. In addition, each Subproject will adapt or tailor the reviews, as appropriate, to its needs. The number and type of reviews described herein are tailored from those described in the Project Management System, DOE Order 4700.1 (DOE 1987). These reviews are described in Standard Engineering Practices, WHC-CM-6.1, Design Verification Requirements, EP 4.1 (WHC 1996c), and will be in accordance with this EP, as tailored for Subprojects and documented in the PMP for each Subproject. Figure 3-3 illustrates the relationship of the reviews to the baselines. Requirements V\&V provide a mechanism to ensure that emerging designs meet requirements.

\subsubsection{System Requirements Review}

The System Requirements Review (SRR) evaluates the SNF Project Functional Requirements Baseline. The SRR is conducted to gain concurrence on the SNF Project objectives, approach, and top-level functions, requirements, architecture, and interfaces. The SRR is conducted by the SNF Project with the SE\&I organization as the lead with DOERL/Spent Fuel Division (SFD) co-chairing the review. The SRR is a SNF Project level review.

A SRR normally would have been conducted prior to the initiation of the Subprojects' design phase, and would consist of a high-level review of SNF Project objectives; systems engineering approach; and Project-level functions, requirements, architecture, and interfaces, as appropriate. Conducting a SRR was not appropriate until the technical baseline stabilized with the approval of the Integrated Process Strategy, followed by issuance of the Spent Nuclear Fuel Project Technical Baseline Description - Fiscal-Year 1996 (WHC 1995d) in November 1995.

The DOE-RL/SFD concurred with the Site Systems Engineering, Systems Engineering Management Plan (WHC 1996b), Spent Nuclear Fuel Project Configuration Management Plan (WHC 1995e), and Spent Nuclear Fuel Project Interface Control Plan (WHC 1995f); approved the Multi-Year Program Plan (MYPP) Revision; evaluated and audited the SNF Project Baseline Management System database; conducted on-board reviews; and conducted Subproject systems engineering assessments. The DOE-RL/SFD also provided top-level programmatic decision making and direction. The DOE-RL/SFD determined the total of these to be equivalent to conducting a SRR. 


\subsubsection{Conceptual Design Review}

A Conceptual Design Review (CDR) is a Subproject review that evaluates the Performance Requirements Baseline, and is conducted by a SNF Subproject.

\subsubsection{Preliminary Design Review}

A Preliminary Design Review (PDR) is a Subproject review that evaluates the Design Requirements Baseline, and is conducted by a SNF Subproject.

\subsubsection{Definitive Design Review}

A Definitive Design Review (DDR) is a Subproject review that evaluates the Design Configuration Baseline, and is conducted by a SNF Subproject.

\subsubsection{As-Built Design Review}

An As-Built Design Review (ADR) evaluates the As-Built Configuration Baseline. The ADR evaluates the as-built Subproject's SSC configurations (architecture) to ensure that the configurations function properly, and meet the requirements of the contract and the approved design. These Subproject reviews are conducted by the SNF Subprojects.

\subsubsection{Operational Readiness Review}

An Operational Readiness Review (ORR) is a major review sponsored by the DOE$\mathrm{RL} / \mathrm{SFD}$. The ORR is used as a verification that a facility is ready for operation. The ORR will address, as a minimum:

- Facility readiness;

- Facility ability to perform its assigned mission;

- Facility operational safety;

- Facility maintenance readiness;

- Operational training; and

- Required permits and procedures completion.

The DOE ORR shall be conducted after the test phase is complete, prior to start-up. 


\subsection{SYSTEMS ENGINEERING TECHNICAL DOCUMENTATION}

Technical documentation consists of documents that contain the information that comprises the SNF Project technical baseline. Table 3-1 presents a list of the SNF Project technical information and their relationship to the technical baselines. The majority of this documentation is not unique to systems engineering; rather, it results from the design documentation required by WHC engineering practices documented in Standard Engineering Practices, WHC-CM-6-1 (WHC 1996c).

\subsection{REQUIREMENTS DOCUMENTATION}

\subsubsection{Spent Nuclear Fuel Project Specification}

The SNF Project Specification states the technical and mission requirements for the SNF Project, derived by the Hanford Technical Integration organization, as documented in the Hanford Site Cleanup Specification, and contained in the Hanford Site Technical Baseline Database. The Hanford Site-level requirements for the SNF Project will be provided to the SNF Project in this specification, which will become the technical basis for the SNF Project Multi-Year Work Plans (MYWP) and MYPP.

\subsubsection{Functions and Requirements Documentation}

The SNF Project Management Plan defines a need for an F\&R or FDC document. This document is a statement of the Subproject, or operations F\&R to a level consistent with the Subproject objective. The Subproject F\&R or FDC contains, as a minimum, all functions allocated to that Subproject, and requirements allocated to the Subproject that affect performance of that Subproject and are not contained in the Subproject acquisition F\&R. Individual Subprojects may prefer to include all F\&R allocated to that Subproject.

The SE\&I organization may support development of the F\&R document and may ensure that it is consistent with the Subproject requirements specification. These sets of F\&R documents are the Subproject F\&R.

\subsubsection{Requirements Specification}

As requirements are allocated to a SSC, the requirements are placed in the requirements specification, which is associated with that SSC. The requirements specification is for use by a Subproject for acquiring SSC. Performance or functional specifications are to be prepared in accordance with Standard Engineering Practices, WHC-CM-6-1, Engineering Specification Requirements, EP-1.2 (WHC 1996c), as single-use, non-construction, engineering specifications. Unless tailored by the Subproject, guidelines for the content and format of these single-use, 
engineering specifications are contained in Engineering Practice Guidelines, WHC-IP-1026, EP G-1.2 and Appendix Q (WHC 1996f).

A requirements specification is a document that is prepared to support development and/or acquisition of a SSC. The requirements specification can be either a performance or functional specification. The requirements specifications state performance (technical) and mission requirements, and allocate them to functions and SSC.

\subsubsection{Baseline Documentation and Database}

Using the results of the mission and functional and requirements analyses, a single integrated SNF Project Baseline has been established for requirements integration and maintenance. This electronic database, the Baseline Management System (BMS), is designed to contain the Project baseline information. The SNF Project Technical Baseline Description (WHC 1995d) provides an integrated description of the SNF Project and the data that form the Project basis. 


\subsection{SYSTEMS ENGINEERING MANAGEMENT PRACTICES}

\subsection{FUNCTIONS AND REQUIREMENTS MANAGEMENT}

Requirements traceability ensures that the technical basis for engineering decisions is maintained, which in turn allows effective resource planning and use. Requirements traceability requires information regarding the requirement source, as well as the requirement's allocation to lower-tier functions or end-item products (e.g., SSC). No requirement is changed without first obtaining approval from the parties responsible for the requirement precursor and successor. All F\&R allocations are stored in an electronic database for retrieval, sorting, and report generation.

As the technical baseline matures, the requirements specifications will be replaced by more-detailed, lower-level specifications. These lower-level specifications, besides being more detailed, may change some of the requirements in the requirements specifications. As these lower-level specifications are developed, the Technical Baseline will be updated so that it contains all requirements currently identified by the SNF Project and Subprojects. After requirements specifications are developed, requirements will be traceable to their respective requirements specification. This ensures that all requirements are traceable through all levels.

\subsection{CONFIGURATION MANAGEMENT}

The technical baseline will be maintained, and changes will be controlled, in accordance with The Spent Nuclear Fuel Project Configuration Management Plan (WHC 1995e).

\subsection{TECHNICAL INTERFACE CONTROL}

The SNF Project was established and will maintain an interface control process coordinated by an Interface Control Working Group (ICWG). The ICWG is a team of representatives managing all internal interfaces, and coordinating with the Hanford Site for resolution of interfaces external to the SNF Project. The ICWG provides traceability, coordination, and documentation of interface definitions using Interface Control Documents (ICDs). The Spent Nuclear Fuel Project Interface Control Plan, WHC-SD-SNF-CM-003 (WHC 1995f) contains more information regarding the interface control activities the SNF Project conducts.

\subsection{RISK MANAGEMENT}

The SNF Project has undertaken an aggressive schedule with the goal of early fuel removal from the $\mathrm{K}$ Basins to reduce risks to public and employee health and safety and the environment. Disciplined implementation of risk management is required to ensure that the accelerated schedule does not result in undue safety, environmental, technical, schedule, nor 
financial risks. Several management methods are being applied to ensure a reasonable understanding and sound management of such risks. These methods include:

1. Implementation of an issues management program for addressing issues at the Project and Subproject levels;

2. Use of disciplined systems engineering and project management processes; and

3. Implementation of a general design strategy towards robust designs based on existing technology.

Risk management processes within Hanford Site projects have their basis in the SiteWide Systems Engineering Risk Management Plan, which is an attachment to Site Systems Engineering, Systems Engineering Management Plan (WHC 1996b).

Risk management in the SNF Project is performed at multiple levels, using a graded approach, with emphasis on issues management. Major programmatic decisions have employed quantitative or semi-quantitative analytical risk-management techniques, such as statistical evaluations or multi-attribute decision analysis. Ongoing Project and Subproject riskmanagement activities emphasize techniques that adjust to the accelerated pace of Project activities, including qualitative techniques such as issues management. Appendix $\mathrm{C}$ describes the SNF Project approach to risk management.

\subsection{WORK BREAKDOWN STRUCTURE}

The SNF Project WBS represents all the work, and only that work, that is required to achieve the end states that have been defined as a result of the mission, functions, requirements, and alternatives analysis of the systems engineering process, including the systems engineering process itself. The SNF Project WBS is contained in the SNF Project MYPP. The WBS results directly from the systems engineering process, as defined previously. Subsequent WBS updates and expansions result from "design" efforts implemented by the Subprojects and management process efforts resulting from implementation of the Subproject Program Management Plans.

The Subprojects will use the SNF Project WBS as a basis for developing WBS for specific Subprojects. The SNF Project WBS also provides an administrative interface to other programs and projects on the Hanford Site.

\subsection{SCHEDULE}

The SNF Project Master Baseline Schedules define the engineering and technical activities performed by the SNF Project. These schedules provide a tool to evaluate progress against planned events and milestones. The planning process, which includes schedule defining, cost estimating, and budgeting, is based on the WBS. 
The Project Master Baseline Schedule is summarized to a Level 1 Management Summary Schedule. The Management Summary Schedule is employed in the Plan of the Week to show weekly status.

\subsection{PERFORMANCE MEASUREMENT}

Performance measurement in the SNF project is accomplished as part of the project control system. A baseline schedule is established and agreed on as part of the MYPP process. Milestones defining expected performance and project deliverables as a function of the schedule are identified in the MYPP (currently termed the MYWP).

Major milestones that mark significant project events, such as design or acquisition of key project SSC, start of key operations, or completion of key documents are tracked by the DOE-RL/SFD. Intermediate milestones that record progress toward completion of major milestones are tracked by WHC. Technical progress is tracked monthly by documenting milestone completion and progress relative to the baseline schedule. Progress is statused monthly for current-year milestones as part of the Site Management System (SMS) Report and the SNF Project Monthly Program Review.

The integrated Project schedule identifies the inter-relationships of Project activities to enable an early identification of potential impacts to major milestones, when intermediate Project milestones are delayed or changed.

Monthly Site Management System reporting includes an assessment of potential impacts to future milestones. In addition, milestones beyond the current fiscal year are evaluated on an annual basis as part of the MYPP process. The Project Control System is defined in the Spent Nuclear Fuel Project Management Plan (WHC 1995a).

\subsection{INTEGRATION WITH OFFSITE SPENT NUCLEAR FUEL ORGANIZATIONS}

The DOE Office of Spent Nuclear Fuel Management (EM-67) currently is pursuing a systems engineering effort for all SNF in the DOE complex. These efforts will have impact on SNF Project systems engineering; and the SNF Project will integrate its systems engineering efforts with the DOE complex-wide efforts.

\subsection{INTEGRATION WITH THE HANFORD SITE}

The SNF Project is part of the Hanford Site cleanup, and receives its top-level guidance and direction from the site level. Site Systems Engineering has identified the necessity for the SNF Project through its functional breakdown. The SNF Project functional breakdown is a subset of the site functional breakdown. Because of this, SNF Project SE\&I will have major continuous involvement with the Hanford Site Technical Integration organization to ensure that 
the SNF Project is performing systems engineering within the bounds of site efforts. Changes made by either the Hanford Site or the SNF Project will affect the other, and will require integration. The Hanford Site Technical Integration organization will be the source of the SNF Project system specification.

The SNF Project SE\&I organization must work with other programs and projects on the Hanford Site to integrate "Cleanup Hanford Site" efforts across the site. In particular, SNF Project SE\&I must integrate its systems engineering efforts with those of other programs and projects. The majority of the external integration effort will focus on generation of Memoranda of Understanding (MOA), which are used as ICDs.

\subsection{INTEGRATION WITHIN SPENT NUCLEAR FUEL PROJECT ORGANIZATIONS}

The SNF Project SE\&I organization will work with other organizations within the SNF Project to ensure the SNF Project efforts remain integrated. Other SNF Project organizations that are required to work to implement the systems engineering process described herein include the SNF Project engineering, operations, and supporting engineering organizations, such as Quality Assurance.

\subsection{INTEGRATION WITHIN THE SPENT NUCLEAR FUEL SUBPROJECTS}

At the SNF Project Subproject level, each Subproject will be responsible for product scope, configuration, cost, schedule, and performance. Subprojects will be structured to facilitate execution of the Project mission, and development of products on the systems engineering product tree. The Subproject Design Authority has the Technical responsibility and authority for the Subproject products. The Subprojects composition shall be consistent with the SNF Project WBS. Subprojects will follow their product through the product development cycle into operations. Typical Subprojects include the following, as appropriate:

- Project Management;

- $\quad$ Process Engineering;

- $\quad$ Systems Engineering and Integration;

- $\quad$ Regulatory Compliance;

- Permitting;

- Public Involvement;

- Scheduling;

- Financial;

- Technology Development; 
- Quality Assurance;

- Safety;

- Operations;

- Test;

- Procurement; and

- Subcontract Management.

Subproject staffing may vary throughout time, depending on the product and its development phase. Matrix and contractor support will be included.

The Project SE\&I organization will integrate systems engineering efforts within the Subproject with:

- The SNF Project;

- Other Subprojects;

- National SNF Program (EM-67); and

- Hanford Site Systems Engineering.

Key to this integration is the membership of the SE\&I Organization staff on the Subprojects. Interface control and configuration management are key processes in Subproject integration.

\subsection{SPENT NUCLEAR FUEL PROJECT MANAGEMENT DOCUMENTS}

For the SNF Project, management documents enable and support development of the integrated SNF Project technical baseline. The management documents that support SNF Project systems engineering technical practices are described in the SNF Project PMP (WHC 1995a). 
WHC-SD-SNF-SEMP-001, Rev. 1

\subsection{REFERENCES}

DOE, 1987, Project Management System, DOE Order 4700.1, U.S. Department of Energy, Washington, D.C.

DOE, 1995, Life Cycle Asset Management, DOE Order 430.1, U.S. Department of Energy, Washington, D.C.

DOE Order 5480.31 Startup and Restart of Nuclear Facilities, U.S. Department of Energy, Washington D.C.

DOE-STD-3006-93, Planning and Conduct of Operational Readiness Reviews, U.S. Department of Energy, Washington, D.C.

PNNL, 1996, Spent Nuclear Fuel Project Integrated Testing Strategy, WHC-SD-SNF-CM-004, Rev 0, prepared by the DOE Pacific Northwest National Laboratory, prepared for Westinghouse Hanford Company, Richland, Washington.

RL, 1996a, Hanford Site Systems Engineering Policy, RLPD 430.1, January 31, 1996, U.S. Department of Energy, Richland Operations Office, Richland, Washington.

RL, 1996b, Systems Engineering Criteria Document and Implementing Directive, RLID 430.1, January 31, 1996, U.S. Department of Energy, Richland Operations Office, Richland, Washington.

WHC, 1994a, Spent Nuclear Fuel Project Mission Analysis Report, WHC-EP-0790, Westinghouse Hanford Company, Richland, Washington.

WHC, 1994b, Systems Engineering Functions and Requirements for the Hanford Cleanup Mission: First Issue, WHC-EP-0722, Westinghouse Hanford Company, Richland, Washington.

WHC, 1994c, Hanford Spent Nuclear Fuel Project Recommended Path Forward, Rev 0, WHC-EP-0830, 2 Volumes, Westinghouse Hanford Company, Richland, Washington.

WHC, 1995a, Spent Nuclear Fuel Project Management Plan, WHC-SD-SNF-PMP-011, Rev 0, Westinghouse Hanford Company, Richland, Washington.

WHC, 1995b, Hanford Site Systems Engineering Manual, WHC-IP-1117, Westinghouse Hanford Company, Richland, Washington:

SEP 1.0, Mission Analysis;

SEP 2.0, Parametric Analysis; 
SEP 3.0, System Function Definition;

SEP 4.0, Requirements Identification and Allocation;

SEP 4.1, Requirements Analysis;

SEP 5.0, Alternatives Development and Allocation of Functions;

SEP 6.0, Trade Studies and Alternatives Development;

SEP 7.0, Verification of Alternatives Compliance and Requirements;

SEP 8.0, Decision Analysis in Alternatives Selection;

SEP 8.1, Risk Assessment of Alternatives;

SEP 11.1, System Specification Development; and

SEP 11.2, Interface Control/Product Specification Document.

WHC, 1995c, Spent Nuclear Fuel Project Path Forward, Additional Nuclear Regulatory Commission Requirements, WHC-SD-SNF-DB-003, Rev 1, Westinghouse Hanford Company, Richland, Washington.

WHC, 1995d, Spent Nuclear Fuel Project Technical Baseline Description - Fiscal Year 1996, WHC-SD-SNF-SD-005, Rev 0, Westinghouse Hanford Company, Richland, Washington.

WHC, 1995e, Spent Nuclear Fuel Project Configuration Management Plan, WHC-SD-SNFCM-001, Westinghouse Hanford Company, Richland, Washington.

WHC, 1995f, Spent Nuclear Fuel Project Interface Control Plan, WHC-SD-SNF-CM-003, Westinghouse Hanford Company, Richland, Washington.

WHC, 1995g, Interim Implementation Directives, Attachment D to W.C. Moffit letter, 2C00095-06, Westinghouse Hanford Company, Richland, Washington.

WHC, 1996a, Project Management, WHC-CM-6-2, Westinghouse Hanford Company, Richland, Washington.

WHC, 1996b, Site Systems Engineering, Systems Engineering Management Plan, WHC-SDWM-SEMP-004, Rev 0, Westinghouse Hanford Company, Richland, Washington.

WHC, 1996c, Standard Engineering Practices, WHC-CM-6-1, Westinghouse Hanford Company, Richland, Washington:

EP-1.2, Engineering Specification Requirements;

EP-1.3, Preparation of Engineering Drawings;

EP-1.5, Interface Control; 
EP-1.6, Engineering Data Transmittal;

EP-1.7, Engineering Document Approval and Release Requirements;

EP-1.12, Supporting Documents;

EP-2.2, Engineering Document Change Control; and

EP-4.1, Design Verification Requirements.

EP-5.9, Interim Design Authority/Design Agent Engineering Process Requirements.

WHC, 1996d, Spent Nuclear Fuel Project Process Flow Diagram Summary, H-2-825867, Rev 0, Westinghouse Hanford Company, Richland, Washington.

WHC, 1996e, Spent Nuclear Fuel Project Level 0 Process Flow Diagram, H-2-825-868, Rev 0, Westinghouse Hanford Company, Richland, Washington.

WHC, 1996f, Engineering Practice Guidelines, WHC-IP-1026, Westinghouse Hanford Company, Richland, Washington.

WHC, 1996g, Spent Nuclear Fuel Project Technical Issue Management Board Charter, Attachment to WHC Internal Memorandum 2002-96-010, April 4, 1996, from J.C. Fulton, to B.S. Carlisle, et al, Westinghouse Hanford Company, Richland, Washington.

WHC, 1996h, Spent Nuclear Fuel Project Integrated Safety Management Plan, WHC-SD-SNFPLN-012, Westinghouse Hanford Company, Richland, Washington.

WHC, 1996i, Spent Nuclear Fuel Project Integrated Testing Strategy, WHC-SD-SNF-CM-004, Rev 0, Westinghouse Hanford Company, Richland, Washington.

WHC, 1996j, Quality Assurance Manual, WHC-CM-4-2, QR-7.0, Section 3.2, Supplier Evaluation and Selection, Criteria 3.c, Westinghouse Hanford Company, Richland, Washington. 


\subsection{GLOSSARY}

Asset Life-Cycle Plans

Alternative Analysis

Architecture

Baseline

Baseline Concept

Description

Change Management

Conceptual Design Report

Configuration

Configuration Management

Cost Baseline

Decision Analysis
Plans that show how much a given asset will cost from conceptual phase through deactivation. These costs form a basis for determing whether system goals and objectives are valid and achievable at specific reviews. The costs also aid in determining if constraints and boundaries are worth maintaining.

A comparison performed on different alternatives, to determine the preferred alternative, based on selected criteria.

The aggregate of all concepts and characteristics associated with a structure, system, and/or component (SSC).

All technical requirements and related cost and schedule requirements.

A working document that provides the system concept description in an easily understood format of pictures and narrative.

It is an iterative system engineering aid, that describes the system as the system evolves and grows in depth of detail, as the definition of a given system matures.

The process of controlling changes to any approved baseline by formal action of a control board.

A report used to establish the functional baseline, defining mission and technical requirements. It normally precedes the demonstration/validation phase.

The functional and/or physical characteristics of hardware, firmware, software, or any other items, as described in technical documentation and achieved in a product.

Discipline of identifying and formalizing the functional and physical characteristics of a configuration item at discrete points in the product evolution, for the purpose of maintaining the integrity of the product system and controlling changes to the baseline.

A budget that has been developed from the cost estimate, resulting from designation of a configuration baseline. The cost baseline is referred to as a baseline because it is integrated with the technical and schedule baselines, and subject to formal change control.

A technique to help manage a complex set of uncertainties. A complex uncertainty is decomposed into simpler uncertainties, which are then treated separately. Decomposition continues until it reaches a level at which either hard information can be brought to bear, or intuition can function effectively. 
Derived Requirements

Function

Functional Design

Criteria (FDC)

Functions and

Requirements

Document(s) (F\&R)

Interface

Interface Management and Control

Integrated Schedule

Analysis

Issue Management

Life-Cycle Cost Analysis

Measure of

Effectiveness

Mission Analysis

Objectives

Parametric Analysis
Characteristics necessary to complete the requirements for design of a structure, system, or component that are dependent on the nature of the item solution for their initial identification. These are typically identified during conceptual design, design studies and analyses, related trade studies, and verifications.

Specificactions, activities, or processes that achieve or support mission accomplishment. "What" must be achieved by the collective effects of all constituent parts. It is synonymous with "purpose."

A document containing the functional requirements for a project.

A document containing the definition of functions, requirements, interfaces, and architectural concepts that are in-line with the stated mission of the Project, Subproject, or Operations.

System boundary across which material, data, and/or energy passes.

A control process coordinated by an Interface Control Working Group, which is a team of representatives that manages all internal interfaces, and coordinates with other agencies to control external interfaces.

Schedules prepared to be used as a tool to evaluate progress against planned events and milestones. The schedules define the engineering and technical activities performed by the Spent Nuclear Fuel Project.

Identification, evaluation, and resolution of issues that encompass multiple Subprojects. The issues may be pivotal in nature, schedule sensitive, or involve an interface external to the Project.

An analysis of the total cost of acquiring, owning, and disposing of an item over its entire lifetime.

A measure of how well the problem is being solved (i.e., how well the mission is being accomplished and its end state achieved).

Study and design efforts that relate to determination of what the project's mission should be and how it should be conducted.

Discrete, measurable events that, if accomplished, will contribute to achieving a goal.

A cost estimate procedure that uses a broad existing database gathered from hardware and software developed for similar purposes, which can be manipulated to establish a price. 
Performance

Preliminary Design

Public Involvement

Requirements

Requirements Verification and Validation

Risk
A quantitative measure characterizing a physical or functional attribute relating to the execution of a mission or function. Performance aftributes include quantity (how many or how much), quality (how well), coverage (how much area, how far), timeliness (how responsive, how frequent), and readiness (availability, MTBF). Performance is an attribute for all system personnel, products and processes, including those for development, production, verification, deployment, operations, support, training, and disposal.

Work done to authenticate the development specification. Successful completion represents approval to begin detailed design.

A process by which the stakeholder views are integrated into the DOE decision-making process. Stakeholder issues, concerns, and values will be understood and considered when making decisions. Public involvement is a dialogue between DOE and the stakeholders. This interaction goes beyond the public receiving information and providing comments after a decision has been reached.

Requirements define how well a function must perform. Requirements set limits on functions and also limits on the outputs from functions. The description of a mandatory condition under which a function must be performed. Requirements are documented in technical specifications, statutes, regulations, Secretary of Energy Notices, DOE orders, or RL Directives or other official direction from the DOE customer.

Verification consists of proof of compliance with specifications, and may be determined by test, analysis, demonstration, inspection, etc. Validation consists of proof the system accomplishes its purpose.

A measure of uncertainty of attaining a goal, objective, or requirements pertaining to technical performance, cost, and schedule. Risk level is categorized by the probability of occurrence and consequences of occurrence. Risk is assessed for program, product, and process aspects of the system. This includes the adverse consequences of process variability. The sources of risk include technical (e.g. feasibility, operability, producibility, testability, and systems effectiveness); cost (e.g. estimates, goals); schedule (e.g. technology/material availability, technical achievements, milestones); and programmatic (e.g. resources, contractual). 
Risk Analysis and Management

Schedule Baseline

Schedule Risk

Safety Analysis Report

Standards/Requirements Identification Document

Specification

Specialty Engineering Integration

Systems Engineering

Systems Engineering Management Plan (SEMP)

Systems Engineering

Process
Risk management includes assessment, analysis, and handling of potential risk. Assessment is the process of examining a situation and identifying the areas of potential risk. Analysis determines the probability of events and the consequences associated with their occurrence. Handling includes techniques and methods to reduce or control risk.

The time-phased plan with logical sequence of interdependent activities, milestones, and events necessary to complete the program. The schedule baseline is integrated with the cost and technical baselines, and is subject to formal change control.

The risk to a program or project of not meeting the major milestones on time.

The report addresses possible hazards associated with system assembly, test, operation, and support. Special consideration is given to possible operational and environmental hazards related to the use of nuclear and other toxic materials.

Identifies environmental, safety, and health requirements for existing and future Hazard Category 2 facilities of the SNF Project. Also identifies standards, regulations, orders, and laws, as well as, "Best Commercial Practices" to establish a minimum set of requirements necessary and sufficient to implement a sound environmental, safety, and health posture.

A description of the essential technical requirements for items, materials, and services that include the verification criteria for determining whether these requirements are met.

The use of all engineering disciplines to simulate, analyze, and design-in supportability to obtain a balance between design, operational performance, supportability, and ownership costs.

The systematic approach used to transform technical goals, and objectives into an optimized, operational, physical system that achieves its mission. The iterative technical and management process applied throughout a system life cycle that produces and maintains a well defined and documented system technical baseline.

The document that defines the technical plan for the conduct of the fully integrated engineering effort.

A comprehensive, iterative problem solving process that:

(a) transforms validated customer needs and requirements into a description of a life-cycle balanced solution set of people, 
Systems Engineering Integration

Systems Test and Evaluation

Technical Baseline

Technical Performance Measurement

Trade Studies

Verification and

Validation

Work Breakdown

Structure (WBS) products, and processes; (b) generates information for decision makers; and (c) provides information for follow-on technical efforts.

After a design approach has been selected, the approach is verified by testing whether the concept of each physical level meets expectations and requirements. The systems engineering integration is the unwinding of the partitioning process used to build the design.

A continuing function performed throughout the acquisition cycle. It is used to reduce acquisition risk and to provide early and continuing estimates of the system's operational effectiveness and operational suitability. Planning, testing, and analysis are all integral function parts.

The body of technical information associated with the people, products, and processes required to accomplish a mission. The documented functions, requirements, and configuration from which the program will acquire an operational system. The technical baseline is maintained under configuration control, and is the basis for technical performance measurement. The technical baseline becomes more detailed and the body of information becomes larger as the system and/or subsystem matures.

The product design assessment that estimates, through engineering analysis, and tests the values of essential performance parameters of the current design of work breakdown structure elements.

An assessment of how well each alternative meets a specific goal.

Verification involves determining the extent to which a system was implemented in accordance with its specifications. Validation involves assessing the effectiveness of a verified system in accomplishing and sustaining its mission. For either class of testing, all critical performance characteristics will be identified, and required performance will be evaluated.

A product-oriented family tree composed of hardware, software, data, and facilities that result from systems engineering efforts during the development and production of a system, and that completely define the program or project. Displays and defines the product(s) to be developed or produced, and relates the elements of work to be accomplished to each other and to the end product. 
WHC-SD-SNF-SEMP-001, Rev. 1

\section{APPENDIX A}

\section{DOCUMENTATION RESPONSIBILITIES}




\section{APPENDIX A \\ DOCUMENTATION RESPONSIBILITIES}

Table A-1 presents a summary of the key documentation resulting from implementation of systems engineering within the Spent Nuclear Fuel (SNF) Project, and the responsibilities of SNF Project organizations for review and approval of these documents. Where appropriate, the responsibilities outlined in the SNF Project Management Plan, and required by WHC-CM-6-2, have been included.

Table A-1 lists SNF Project Systems Engineering Management Plan (SEMP) documentation, including key equivalent Subproject documents. Only the minimum responsibilities required for consistency across the project are indicated. Additional responsibilities may be included in appropriate Program Management Plans (PMP). Subproject PMPs that deviate from these document responsibilities must detail any deviations.

The Lead (L) coordinates the document production from beginning to end, and is an approver. Reviewers ( $R$ ) are required to participate to the extent requested by the Lead, and sign off on the document. Approvers (A) are required to sign off on documentation.

This documentation responsibilities table may be revised when the information is superseded by higher-level Project documentation. 


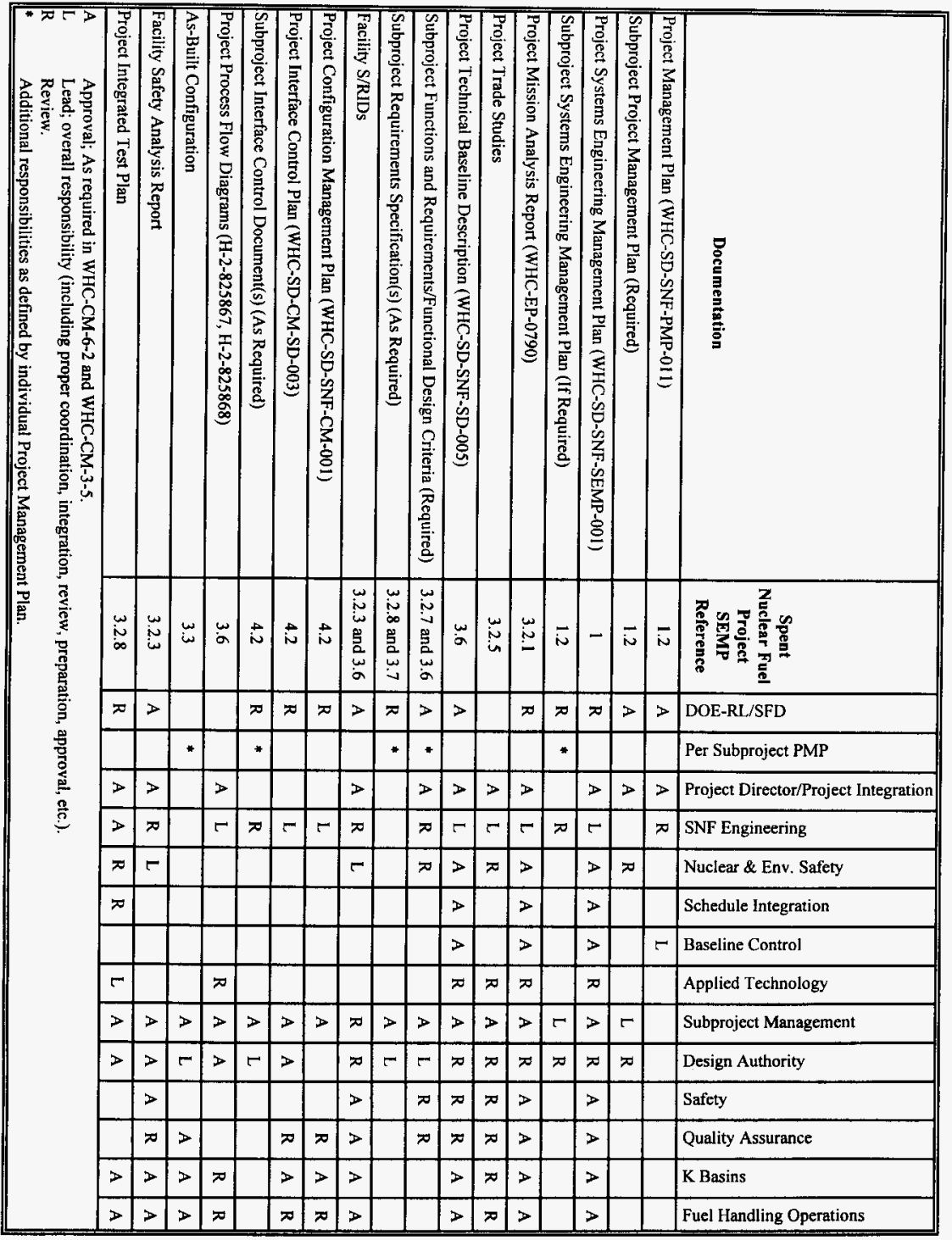

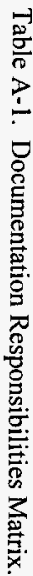


WHC-SD-SNF-SEMP-001, Rev. 1

\author{
APPENDIX B
}

\title{
SPENT NUCLEAR FUEL PROJECT DESIGN AUTHORITY/ DESIGN AGENT PROCESS
}




\section{APPENDIX B}

\section{SPENT NUCLEAR FUEL PROJECT DESIGN AUTHORITY/ \\ DESIGN AGENT PROCESS}

\section{B.1 INTRODUCTION}

The Design Authority/Design Agent concept resulted from a need, identified by Hanford Site management, to simplify and clarify the lines of technical responsibility and authority during the various stages of the integrated engineering process (WHC 1995g and WHC 1996c).

The SNF Project has developed a tailored process that implements the Site Design Authority/Design Agent concept. The following paragraphs provide guidance to Spent Nuclear Fuel (SNF) Project Design Authorities and Design Agents regarding their functions and responsibilities.

\section{B.2 DESIGN AUTHORITY}

\section{B.2.1 Design Authority Description}

The Design Authority is the person uniquely responsible and accountable for final acceptability of a structure, system, or component (SSC), including its design baseline and safe operation (WHC 1995g). The key objective of the SNF Project Design Authority process is to empower qualified engineering professionals, representing the interests of the system owner/operator, with absolute, cradle-to-grave technical decision-making responsibility and authority at the lowest practical SSC level.

Within the SNF Project, there are currently three classes of design authorities--Project, Subproject, and Operations. The SNF Project Design Authority is appointed by the Project Director, and responsible for the design of the integrated SNF Project. Each Subproject and Operations Design Authority is delegated authority for his/her SSC by the Project Design Authority. Subproject Design Authorities may become Operations Design Authorities, as their systems pass through operability testing and readiness review.

\section{B.2.2 Design Authority Roles and Responsibilities}

B.2.2.1 Project Design Authority. The Project Design Authority is the owner of the Project design (technical) baseline, and is the integrator and administrator of the Design Authority/Design Agent process within the SNF Project. Responsibilities include: 
- Implementation of Systems Engineering within the Project;

- Configuration control of the Project technical baseline, primarily through maintenance of the Technical Baseline Description document;

Integration of Project technical activities, primarily through administration of the design authorities interface control process, and memoranda of understanding with external interfaces;

- Coordination of the Project technical management to oversee implementation of the process, by ensuring

- $\quad$ SSCs are identified and well defined physically,

- Qualified design authorities, alternates, and substitutes are approved, trained, and delegated authority for each identified SSC, and

- Qualified Design Agents are approved; and

- Maintaining the position as the Project point-of-contact with the Site Engineer.

B.2.2.2 Subproject/Operations Design Authorities. Primary responsibilities of the Design Authority are based on the SSC technical aspects. Detailed Design Authority responsibilities are included in individual Subproject Project Management Plan (PMP). As the lead systems engineer for each SSC, the Design Authority is the technical representative for the SSC owner/operator. Key Design Authority responsibilities include:

- Implementation of the systems engineering process within the Subprojects/Facilities;

- Approving Design Agent products and deliverables;

- Development and maintenance of the system's design (technical) baseline, to include

- Developing key design documents such as Functions and Requirements (F\&R)/Functional Design Criteria (FDC), performance specifications, and safety analyses,

- Configuration/change control on the baseline, and taking timely action to implement and communicate any changes, and

- $\quad$ Requirements management including traceability to the Project technical baseline;

- Control of technical and operational interfaces;

- Acquiring/approving SSC products, including ensuring the products meet the design (technical) basis; and

- Supporting the resolution of technical issues associated with the SSC. 


\section{B.3 DESIGN AGENT}

\section{B.3.1 Design Agent Description}

The Design Agent is the person responsible and accountable to perform the delegated activities, and provide the technically adequate designs in accordance with agreed requirements specified by the Design Authority. Design documents produced by the Design Agent are subject to stamping by professional engineers when specifically mandated by law or requested by the Design Authority. A Design Authority who performs Design Agent work shall be qualified formally as a Design Agent, and be designated appropriately as the Design Agent. In the SNF Project, all Design Agents are at the Subproject/Facility level.

When an offsite organization assumes Design Agent role and responsibilities, it is incumbent upon the Project manager and the Subproject/Operations Design Authority to ensure that the offsite organization has technically qualified personnel who would perform as the Design Agent(s). This requirement is specified in the WHC QA Manual, WHC-CM-4-2, QR-7.0, Section 3.2, Supplier Evaluation and Selection, Criteria 3.c (WHC 1996j). The SNF Project Design Authority or Hanford Site Engineer are normally not involved in approving offsite organization as Design Agent.

\section{B.3.2 Design Agent Roles and Responsibilities}

The responsibilities of the SNF Subproject Design Agents include:

- Producing design output documents, such as drawings, design specifications, reports, and as-built drawings;

- Preparing test procedures and documents;

- Defining inspections requirements;

- $\quad$ Supporting design reviews;

- Interpreting code requirements;

- Ensuring the technical adequacy of design to requirements specified by the Design Authority; and

- Performing alternative studies and analyses. 
WHC-SD-SNF-SEMP-001, Rev. 1

\section{APPENDIX C}

\section{RISK MANAGEMENT IN THE SPENT NUCLEAR FUEL PROJECT}




\section{APPENDIX C \\ RISK MANAGEMENT IN THE SPENT NUCLEAR FUEL PROJECT}

\section{C.I BACKGROUND AND OVERVIEW}

The Spent Nuclear Fuel (SNF) Project has undertaken an aggressive schedule with the goal of early fuel removal from the $\mathrm{K}$ Basins to reduce risk to the public and worker health and safety, and the environment. Disciplined implementation of risk management is required to ensure that the accelerated schedule does not result in undue safety, environmental, technical, schedule, or financial risks. Several management methods are being applied to ensure a reasonable understanding and sound management of such risks. These methods include:

1. Implementation of an issues management program for addressing issues at the Project and Subproject levels;

2. Use of disciplined systems engineering and project management processes; and

3. Implementation of a general design strategy towards robust designs, based on existing technology.

Risk management processes within Hanford Site projects have their basis in the SiteWide Systems Engineering Risk Management Plan, which is an attachment to Site Systems Engineering, Systems Engineering Management Plan, (WHC 1996b).

Risk management in the SNF Project is performed at multiple levels using a graded approach, with emphasis on issue management. Major programmatic decisions have employed quantitative or semi-quantitative analytical risk management techniques, such as statistical evaluations or multi-attribute decision analysis. Ongoing Project and Subproject risk management activities emphasize techniques that adjust to the accelerated pace of Project activities, including qualitative techniques such as issues management.

\section{C.2 RISK MANAGEMENT PROCESSES FOR MAJOR STRATEGIC DECISIONS}

For major strategic decisions within the SNF Project, a combination of risk identification and analysis tools have been used to provide data to evaluate safety, technical, environmental, programmatic, and schedule risks. This section describes implementation of the risk management approach, as applied in the two major strategic decision points in the Project:

- Development of the SNF Project Recommended Path Forward in October 1994; and

- Development of the Integrated Process Strategy in July 1995. 
These are examples of the approach that would be used for major strategic decisions in the future.

\section{C.2.1 Spent Nuclear Fuel Project Recommended Path Forward.}

The Path Forward was the SNF Project original strategy for resolving safety and environmental concerns associated with the $\mathrm{K}$ Basins fuel; and providing for the safe interim storage of the material, pending establishment of a national strategy for long-term fuel management. To arrive at the Path Forward, risk-based decision techniques were used in conjunction with a variety of technical and programmatic reviews by senior experts from outside the Hanford Site. These reviews served to both identify risks, and verify that the decisions reached adequately addressed those risks.

Evaluation of the alternatives included analysis of cost, schedule, regulatory, and stakeholder drivers, and affected tribe values; independent assessments by outside experts; and the use of decision analysis techniques to ensure a comprehensive, balanced treatment of the various alternatives. An important aspect of this process was the identification of issues, their potential impacts, and how they might be mitigated. From a risk management perspective, the decision evaluation included:

- Health, safety, and environmental risk assessment;

- Multi-attribute decision analysis;

- Programmatic risk assessment; and

- External reviews.

Alternatives were modified, if necessary, to meet minimum requirements or to optimize performance with respect to technical, safety, environmental, schedule, or stakeholder criteria.

C.2.1.1 Health, Safety, and Environmental Risk Assessment. The Path Forward evaluation considered the health risk to the public, workers and environment from the release of ionizing radiation and hazardous materials. Also considered were the health risk to workers from industrial activities involved in the processes. A preliminary hazards analysis process was used to identify potential accident conditions. A qualitative determination of the accident sequence consequence and frequency was completed to provide a relative risk index. The total relative risk index and the relative risk index as a function of time were evaluated. Conclusions relative to the public, worker, and environmental risk are provided in the Hanford Spent Nuclear Fuel Project Recommended Path Forward, Volume 2, Appendix F (WHC 1994c).

C.2.1.2 Multi-Attribute Decision Analysis. The evaluation process identified the fundamental objectives important to making the Path Forward decision. Criteria associated with the objectives were developed such that if the individual criteria are realized, then the objectives will be achieved. The fundamental objectives for the Path Forward were: 
- Minimize total costs;

- Minimize public, worker and environmental health risks;

- Minimize the schedule;

- Maximize affected tribes and stakeholder confidence;

- Maximize technical performance; and

- Maximize the likelihood of programmatic success.

The multi-attribute decision analysis evaluated the alternatives with respect to how well they achieved these objectives. Criteria associated with each of the objectives that could be quantified were identified. The relative importance of the various objectives and criteria were identified and weighted to ensure that achieving the most important criteria had greater significance than meeting the lesser criteria. Each alternative was scored for each of the objectives and criteria. The overall score reflected the relative ability of each of the alternatives to meet the objectives set forth for the Path Forward.

In the case of the path forward, the best features of the original alternatives evaluated were extracted and combined to create the Recommended Path Forward. This represented a significant reduction in risk immediately in the Project because it combined the project components that best met the overall project objectives.

C.2.1.3 Programmatic Risk Evaluation. The programmatic risk evaluation assessed the impact of uncertainties within key Project elements in the likelihood that the alternatives will achieve the established Project schedule and cost goals. The evaluation assisted the decision process in determinig not only whether an alternative can achieve the required goals, but also the magnitude of risk of delays and overruns associated with it. The focus was to identify those key components that, if effectively managed, would have the greatest influence on successfully meeting the aggressive schedule. The evaluation process clearly identified those technical and management issues that had to be addressed early in the Project. The programmatic risk evaluation is described in detail in the Hanford Spent Nuclear Fuel Project Recommended Path Forward, Volume 2, Appendix G (WHC 1994c).

C.2.1.4 External Reviews. As a risk mitigation measure, an independent, external, senior review group was chartered by the Project. This group reviewed methodology and results of the path forward decision analysis so that risks were identified and addressed adequately.

\section{C.2.2 Spent Nuclear Fuel Project Integrated Process Strategy}

With approval of the Path Forward in February 1995, the U.S. Department of Energy (DOE) assigned an accelerated schedule goal to begin fuel removal from $\mathrm{K}$ Basins by December 1997 (one year earlier than the Path Forward recommendation), to complete fuel conditioning for 
dry storage as soon as feasible, and to implement those accelerations within current budget projections.

In response to these goals, the Integrated Process Strategy was developed to establish the technical framework to construct facilities and implement processes compatible with these goals. Major innovations such as repackaging the fuel into storage baskets to reduce necessary storage space and containers for the fuel; removal of fuel corrosion products and other sludges; and application of a two-step fuel drying and conditioning process were developed to enable the Project to meet these goals.

The schedule acceleration and the new process innovations required increased attention to risk management on the part of the Project.

The initial Path Forward study, subsequent technical and engineering tradeoff studies, and the integration results described in this report all use a systems engineering methodology as a basis for defining mission, functions and requirements, and decision making. Evaluation criteria were developed relative to the Systems Engineering Functions and Requirements for the overall SNF Project. The results of the studies and integration efforts feed back into the systems engineering process. The Project technical baseline, functional requirements, and requirements specifications were revised accordingly, based on strategies and guidelines defined by this document, after approval by DOE.

The evaluation process included use of decision criteria similar to those established for the Path Forward study. Key issues were identified along with various engineering alternatives for resolving the issues. The evaluation of alternatives included the use of systematic decision analysis techniques to ensure a comprehensive, balanced treatment. The decision evaluations included:

- Health, safety, and environmental risk assessment,

- Multi-attribute decision analysis; and

- External independent reviews.

C.2.2.1 Health, Safety, and Environmental Risk Assessment. The Integrated Process Strategy was evaluated from a public health and safety, worker safety, and environmental protection perspective. Worker safety was evaluated for both Hanford Site workers (i.e., nonSNF Project workers) and facility workers (i.e., those workers performing work in the facility being assessed). All Project activities and new facilities used a defense-in-depth safety philosophy to achieve a high level of assurance that adequate safety margins and environmental protection are maintained.

To support evaluation of the process options examined in the Integrated Process Strategy, a relative risk comparison was performed. The methodology involved use of a matrix based, semi-quantitative comparison, using relative risk scores. Estimates of accident consequences (radiological dose and environmental impact) and frequency (i.e., probability of occurrence per 
year) were developed for the dominant accident sequences identified in the $\mathrm{K}$ Basins and other Project safety documentation. The product of frequency times consequences is the risk for a given postulated accident sequence. The sum of the risks from all dominant accident scenarios associated with a given process option for removal, conditioning, and storage of $\mathrm{K}$ Basins fuel was used as an overall risk score for the option. Risk scores were compared for numerous fuel removal options considered by this study.

For accident scenarios not specifically analyzed in the SNF Project safety documents, analysts estimated accident frequency and consequences, based on conservative assumptions. The risk assessment also included a comparison with the risk of continued storage of fuel at $\mathrm{K}$ Basins. The greatest risk reduction came from early removal of fuel and sludge from the K Basins.

This evaluation identified areas of comparative risk for the options being considered and enabled the Project to understand the risks associated with the Integrated Process Strategy and to develop plans to mitigate those risk areas.

C.2.2.2 Multi-Attribute Decision Analysis. A multi-attribute decision analysis was performed to evaluate the process options. This analysis allows decision makers simultaneously to evaluate proposed actions against several major programmatic and technical objectives.

The original Path Forward multi-attribute decision analysis criteria and evaluation weights were updated to reflect the direction received from the DOE, refining the goals of the Project. The major objectives used for the multi-attribute decision analysis were:

- Minimize schedule;

- Minimize total Project costs;

- Minimize health, safety, and environmental health risks;

- Maximize stakeholder confidence; and

- Optimize technical performance.

Evaluation criteria were ranked and weighted to allow application in the multi-attribute analysis. The results of this analysis identified that the process steps that formed the Integrated Process Strategy best met the Project objectives and criteria.

C.2.2.3 External Reviews. As in the case of the Path Forward study, an independent, external senior review group reviewed the results of the Integrated Process Strategy decision analysis to verify that technical analyses were sound, and that risks were adequately identified and addressed. 


\section{C.3 ONGOING SPENT NUCLEAR FUEL PROJECT MANAGEMENT}

\section{C.3.1 Systems Engineering Management}

The strategy to accomplish the SNF Project mission and objectives includes the implementation of a disciplined systems engineering approach, as described in this Spent Nuclear Fuel Project Systems Engineering Management Plan (SEMP).

The role of systems engineering in risk management is to ensure that the mission and scope of the Project is well defined; that the functions necessary to accomplish the mission are identified; and that the requirements that must be met by each of the functions are identified. These form the Project technical baseline on which configuration control is maintained. Subprojects use the Project-level functions and requirements to develop subordinate functions and requirements. Implementation of systems engineering methods within the SNF Project is described in the body of this document. There are two specific systems engineering principles that enhance risk management within the Project, as described in the following paragraphs.

C.3.1.1 Interface Control. Formal interface control is applied with the Project when the design of physical or functional features between equipment items, or between equipment items and facilities may result in a mismatch, omission, interference, or duplication if not properly coordinated. The Spent Nuclear Fuel Project Interface Control Plan, WHC-SD-SNF-CM-003 (WHC 1995f) describes the Project policy for interface control.

Interfaces are identified through the development of Process Flow Diagrams, functional analysis and design activities. Interface scope sheets identify the participants, and describe the physical interface and its parameters in sufficient detail to ensure compatibility, throughout the design, procurement, and fabrication phase. An Interface Agreement records interface boundary agreements between responsible managers. Memoranda of Understanding are used for establishing interface agreements external to the SNF Project.

The SNF Project Interface Control Working Group was established to bring together the Subproject design authorities and Subproject managers to enhance interface definition and resolution of interface issues. Any interface disputes or issues unresolvable at the Design Authority and Subproject management level are elevated to the SNF Project Technical Issues Management Board for consideration.

C.3.1.2 Configuration Management . The Project has implemented a configuration management system to establish and maintain technical consistency among design requirements, physical configuration, and documentation. The Project Configuration Management Plan, WHC-SD-SNF-CM-001 (WHC 1995e) assists in identifying and managing structures, systems, and components that require configuration control; and controlling and statusing changes to ensure that design, performance, and operational requirements are met. 


\section{C.3.2 Technical Issues Management Board}

The SNF Project Technical Issue Management Board (Board) identifies, evaluates, and resolves issues that encompass multiple Subprojects that are pivotal in nature, schedule sensitive, or involve an interface external to the Project. In resolving these SNF Project-level issues, Board decisions formally become part of the SNF Project Technical Baseline. Results are documented and retained in the SNF Project Files.

The Board is comprised of SNF Project Managers responsible for technical scope, cost, and schedule. An additional member is a DOE representative who serves to enhance communication regarding pending decisions. The Board identifies and prioritizes Project-level issues; provides management attention and visibility to resolution of issues; sponsors studies that support timely issue resolution; makes and documents decisions to be incorporated into the Technical Baseline and implemented by the Project; and incorporates risk management into the decision making process to maximize Project success through cost, schedule, and technical considerations. The Board also oversees Subproject-level issues management to ensure that each Subproject consistently is managing issues that may have an impact on the Subproject baseline.

Details of the procedures for technical issues management are defined in the Spent Nuclear Fuel Project Technical Issue Management Board Charter (WHC 1996g).

\section{C.3.3 Integrated Safety Management Approach}

The SNF Project has adapted the recommendations of the Defense Nuclear Facility Safety Board (DNFSB), with respect to defense-in-depth safety principles resulting in the generation of an authorization basis that provides for safe design, construction, and operation. The Spent Nuclear Fuel Project Integrated Safety Management Plan (ISMP), WHC-SD-SNFPLN-012 (WHC 1996h), defines the safety processes, requirements, and responsibilities to be applied to the Project. The ISMP is based on four concepts:

- Defense-in-depth,

- Minimizing exposure,

- Hazards/safety analysis, and

- Clear delineation of safety responsibility.

The ISMP describes the graded approach to safety analysis used by the Project to select and apply analysis techniques that provide sufficient detail to assess each postulated accident or failure, the resulting consequences, and means of prevention or mitigation. This integrated approach reduces the level of safety risk associated with operations of Project facilities. Some of the key parts of the graded approach include:

- Unreviewed Safety Questions Evaluation; 
- Hazards Analysis and Categorization;

- Preliminary Safety Evaluation and Classification;

- $\quad$ Fire Hazards and Accident Analysis;

- Criticality Safety Evaluation;

- Safety Analysis Report; and

- Technical Safety Requirements.

The ISMP identifies the authorization approach being used for each of the Subprojects, the scope of schedule for Subproject safety analysis activities, and the review and approval requirements. This also minimizes programmatic risks associated with unplanned authorization basis requirements as startup of the facility approaches.

\section{C.3.4 Integrated Testing Strategy}

Within the SNF Project, each of the Subprojects continues to define data needs as their individual designs mature. In parallel, the safety analysis effort is refining the basis for the Safety Analysis Report, and identifying data necessary to support the Project authorization basis. The fast pace of the project, coupled with a high level of parallel design activities, increases the risk that Subprojects may proceed with inconsistent assumptions, may duplicate certain tests, or may omit tests necessary to support critical assumptions. Recognizing this, the Spent Nuclear Fuel Project Integrated Testing Strategy (WHC, 1996i) documents the Project-level strategy that will ensure all data requirements are identified, and test plans are developed that efficiently fulfill the requirements.

\section{C.3.5 Operational Readiness Review}

It is DOE policy that operations not be started nor resumed in nuclear facilities until the facility has been brought to a state of readiness to safely conduct operations; and that the state of readiness has been verified. An operational readiness review (ORR) is a disciplined, systematic, documented, performance-based examination of facilities, equipment, personnel, procedures, and management control systems to ensure that a facility will be operated safely within its approved safety envelope, as defined by the facility safety basis.

An integrated ORR will be performed prior to the beginning of fuel loading. This integrated ORR will enhance the Project's assurance that all Subprojects and operations organizations have provided facilities and equipment that are ready for use, will perform its assigned mission, will be safe to operate, can be properly maintained, has qualified and trained staff, and has necessary permits and procedures. The Project is preparing an ORR Plan of Action to formalize the decisions necessary to execute the beginning of fuel removal operations. 


\section{C.3.6 Reporting and Evaluations}

A baseline schedule and budget is established and agreed upon as part of the Multi-Year Program Planning (MYPP) process. Major milestones that mark significant project events (i.e., design or acquisition of key project components, start of key operations, or completion of key documents) are tracked by the DOE. Intermediate milestones that record progress toward completion of major milestones are tracked by the Project. Cost performance and schedule/milestone status are tracked monthly as part of the Site Management Systems (SMS) Report and the SNF Project Monthly Program review. This includes an assessment of potential impacts to future milestones from current events or situations. Plan-of-the-week meetings are conducted by the Project to address ongoing events and emerging issues.

Ongoing evaluation and reporting enhance risk management by ensuring that schedule, cost, and technical issues are raised and addressed in a timely manner. The Project Control System is defined in the Spent Nuclear Fuel Project Management Plan (WHC 1995a).

\section{C.3.7 External Reviews}

Ongoing independent external reviews provide an important continuing assurance that potential Project risk areas are being adequately identified and addressed. Key external reviewers include:

- The SNF Project-sponsored Senior Design Review Board, whose primary focus is on technical and Subproject management activities within the Project;

- The DOE, Richland Operations Office (RL)-sponsored Independent Review Panel (IRP), whose primary focus is on regulatory activities within the Project; and

- The Congressionally-sponsored DNFSB, whose primary focus is oversight of activities for completion of major Project milestones.

\section{C.4 ONGOING SUBPROJECT MANAGEMENT}

In addition to participating in, and providing input for, ongoing Project level activities described in Section 3.0, the Subprojects perform several additional steps that enhance risk management as described in the following paragraphs.

\section{C.4.1 Subproject Issues Management Process}

The Subproject Issue Management process ensures that SNF Subprojects have consistent issue management systems that identify key issues, resolve them in a timely manner, and document the decision basis. Issues include concerns, interfaces, or unvalidated assumptions that could have significant impact to cost, schedule, or technical baselines; and are not being resolved through technical development within the planned Subproject scope. 
All Subprojects will have an issue management system that consists of the following key elements:

- Issue identification;

- An issue tracking list separate from any day-to-day action item management tool;

- Periodic reviews of progress toward issue resolution and closure against schedule;

- Documentation of issue closure, including alternative evaluation and decision rationale, as appropriate; and

- $\quad$ Screening for overarching issues and elevating them to the Technical Issue Management Board for resolution

The Technical Issue Management Board will review periodically each Subproject's issue management system to confirm that the requirements for Subproject issue management are being met; perform an overview of the issue screening process for overarching issues; and ensure that key issues are being identified and addressed.

The Subproject issue lists will be reviewed for completeness by representatives of the following cross-cutting functions:

- Characterization;

- Technology Integration;

- Integrated Testing;

- Operational Readiness;

- $\quad$ Regulatory, Permitting and Safety;

- Interface Management; and

- Systems Engineering.

\section{C.4.2 Design/Verification Process}

Subprojects involved in design and acquisition of new facilities or equipment use a substantial design verification process to ensure that requirements are met, and that equipment is functional and meets user and customer (DOE) needs. Systems engineering products verified in the design verification process include:

- $\quad$ FDC or F\&R documents;

- Requirements Specifications;

- Conceptual Design Reports; and 
- Definitive Design Packages.

Agreement and understanding of the requirements and criteria early in the acquisition process lessens the risk of unplanned changes. Periodic design review by key Project personnel and by supporting organizations such as Quality Assurance and Safety reduce the risk of facilities or equipment that do not meet Project needs or requirements. Each Subproject develops a Project Management Plan that delineates the specific design/verification processes that will be used in that Subproject. This plan is reviewed and approved by RL. 